\title{
LA-4961-MS
}

AN INFORMAL REPORT

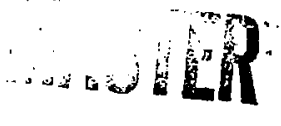

Beam Measurements on the High-Intensity Proton Injector of LAMPF 
This report was prepared as an account of work sponsored by the United States Gnvernment. Neither the United States nor the United States Atomic Energy Commission, nor any of their employees, nor any of their contractors, subcontractors, or their employees, makes any warranty, express or implied, or assumes any legal liability or responsibility for the accuracy, compleieness or usefulness of any information, apparatus, product or process disclosed, or represents that its use would not infringe privately owned rights.

In the inter est of prompt distributior, this LAMS report was no: edited by the Technical Information staff.

Printed in the United States of America. Available from

National Technical Information Service

U. S. Department of Commerce 5285 Port Royal Road Springfield, Virginia 22151

Price: Printed Copy $\$ 3.00$; Microfiche $\$ 0.95$ 
LA-4961-MS

An Informal Report UC-28

ISSUED: May 1972

\section{Beam Measurements on the High-Intensity Proton Injector of LAMPF}

by
R. R. Stevens, Jr.
S. D. Palermo
M. A. Paciotti
D. W. Mueller
R. S. Mills
E. A. Meyer
D. K. Kohl
B. Goplen

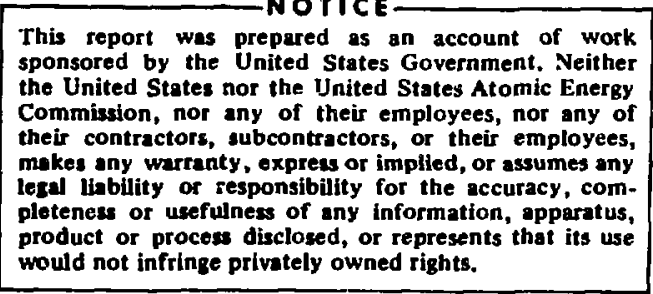




\section{BEAM MEASUREMENTS ON THE HIGH-INTENSITY \\ PROTON INJECTOR OF LAMPF}

by

R. R. Stevens, Jr, S. D. Palerwo, M. A. Paciotti, D. W. Mueller,

R. S. Mills, E, A. Meyer, D. K. Kohl, B. Goplen

\section{ABSTRACT}

Pepper pot and quartz plate measurements were made near the exit of the accelerating column over a wide range of operating parameters. Phase space envelopes were accurately determined; however, density distributions are still in doubt.

\section{SIMMARY}

One of the basic problems encountered in doing transport calculations for the proton bean in the injector area of IAMPF has beer that of determining the properties of the bean going into the transport line. Initial design calculations for the transport system assumed a beam envelope of $\pm 0.7 \mathrm{~cm}$ size and $\pm 7 \mathrm{mrad}$ divergence. Subsequent studies ${ }^{1}$ of the beam transpor. system indicated that the size and divergence of the beam entering the transport system were larger than originally considered, and that this larger input bean required a change in the focusing strength of the lenses in the transport system to prevent beam loss at the prebuncher. To do more realistic calculations for this bean transport system, the size, divergence, emittance, and effective current of the input beam to this systen must be known. Therefore, extensive measurements were undertaken at the exit of the accelerating column to determine these parameters for a variety of operating conditions. This report discusses the measurements performed and the results obtained.

The prugram began and ended with a standard set of experiments involving $x$-ray radiation, proton ratio, and the transverse phase space at EM11, EM12 and EM3. 1 The main purpose of chese before-and-after tests was to establish the validity of the more basic measurements. The first such measurement in- volved a quartz plate fositioned 16 in. from the exit of the column. Photographs of the beam impinging upon the plate were taken over a range of operating conditions. These gave corroborating ev: dence for the pepper-pot analysis and some intensity information.

The second set of measurements was made with a pepper pot located 5 in. from the exit of the column. A total of 104 photographs was taken over a wide range of operating conditions. All results obtrined in these parametric studies are given in this report. Beam intensity information was obtained thfough a microdensitometer reduction of the pepperpot dots.

Finally, a new single row pepper pot was installed, and intensity scans were performed using a TV vidicon device. This completed the present series of tests.

The measurements confirmed that the beam at the erit of the column is cylindrically symmetric. The three ion species occupy the same phase space. The beam is centered in the accelerating column; there is no measurable steering effect due to any of the operating parameters. Further, it is possible to explain the variation of $x$-ray radiation with bean current. It is apparent that the upper end of the curve is caused by the main body of the beam striking electrodes in the column, while the radia- 
tion peak at the lower end is due solely to the halo, or tails, which constitute a much different phase space from that of the main body. The lower peak can be essentially eliminated by setting extractor voltage parametrically as a function of extracted ion current.

We define the veam envelope to contain the outermost visible portion of the main body of the beam as distinct from the tails. This identification is possible since the phase space of the main body of the bean in either plane is the area associated with a straight line passing through the origin. It is emphasized that the envelope, as such, gives no information concerning the intensity distribution of the beam within, save to confirm the unique-. ness of that body of phase sprec.

It was found that the phase space envelopes are basically unc ffected by any of the operating parameters, with the exception of extracted ion current. This variable produces a dramatic eifect on all aspects of the beam. The main interesi lies in the beam parameters near the operating current. At the centis line of the tenth electrode, the beam phase space envelope has a size of $\pm 1.03 \mathrm{~cm}$ as $\mathrm{d}$ a divergence of $\pm 14.6 \mathrm{mrad}$. The emittance is $1.25 \pi \mathrm{cm}$ mrad and the priton fraction is about $70 \%$. Both the micredensitometer and the vidicon data indicate a very sharp drop-off of intensity for the main body of the beam. Both sets of data shor that the radial position of this drop-uff can be substantially reduced by changing arc magnet current. However, the two techniques used to measure intensity give results which differ by almost a tacks of two in rins radius. This question has nci yet been resolved. Thus, although we can define the phase space occupied by the beam, the precise population of that space is still incertain.

\section{THE ION SOURCE}

The source for the high intensity proton beam is a duoplasnatron hot-cathode hydrogen arc discharge source. Figure 1 is a cross-section drawing of this source. The special feature of the duoplasmatron source is the axial magnetic field between the nose of the iron intermediate electrode (the cathode is inside) and the iron plasma-aperture fixture. There is some evidence that the axial field constricts the arc so that it passes through

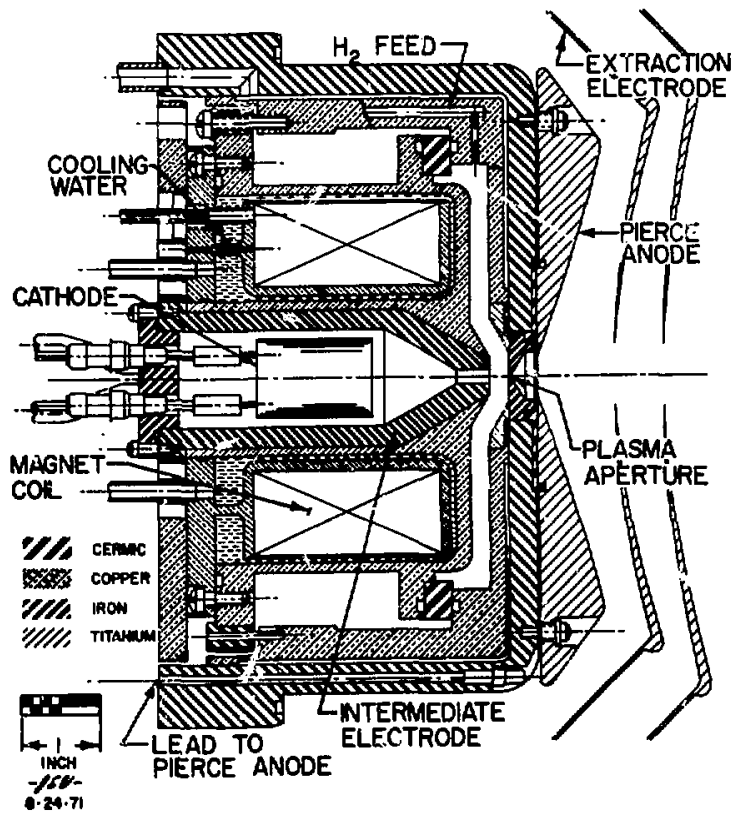

Fig. 1. The duoplasmatron ion source.

the plasma-aperture and terminates on the far side of the hole (inside the cup). Thus, a hydrogen plasma is produced in the cup with a relatively small hydrogen gas flow. Hydrogen ions are extracted from the plasma by a strong electric field between the source and the extractor, about $25 \mathrm{kV}$ across 1 in.

The designation for the particular source used in these studies is ITI $a / 11 C T-2$, which stands for source body III a, plasma aperture 11 , and centertop cathode $\# 2$. Figuze 2 is an enlargement showing more detail of the cup region. The Pierce anode hole diameter is $1.4 \mathrm{~cm}$ and the inner cup diameter is $1.6 \mathrm{~cm}$. The original diameter of the plasma ap-

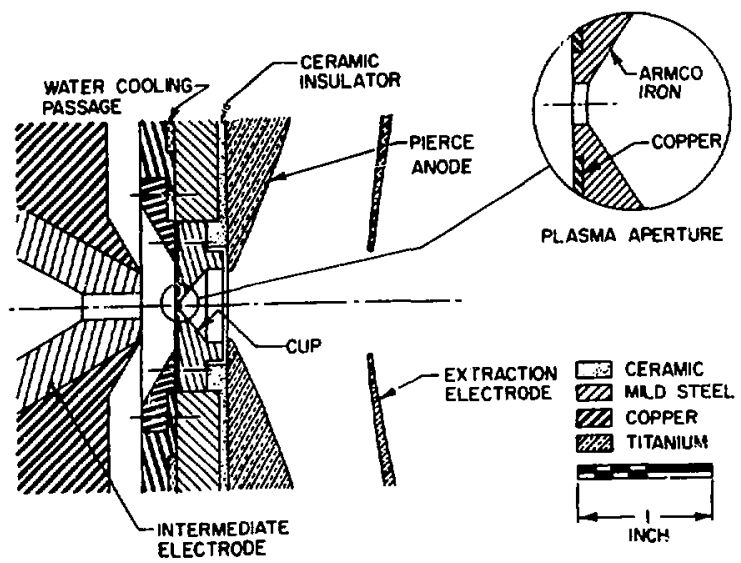

Fig. 2. Plasma aperture region of the source. 
erture was $0.025 \mathrm{in}$. On December 17, 1971, this diameter was measured to be $0.031 \mathrm{in}$. The original depth was $0.010 \mathrm{in}$. and the iron rim radial thickaess was $0.040 \mathrm{in}$.

This assembly had been in use in the $750 \mathrm{kV}$ injector since July 22, 1971, and was still in use on January 28, 1972. Thus, it was well stabilized before the present measurements were made. On those occasions when the source was removed from the column, the cathode, intermediate electrode assembly, plasma ayerture, and the Pierce anode were not disturbed relative to each other and tc the main body of the source.

The proton fraction was measured as a function af extracted ion current both before and after the pepper-pot tests. These results are presented in Fig. 3. The cause of the slight drop in proton fraction after the tests is not known, but may simply be the result of improper tuning of the beam line. Other proton fraction determinations have subsequently been made which are closer to the original curve.

The source produces the erititance area of the beam. Previous measurements with emittance gear at the EMl station have indicated an emittance of 1.25 $\pi \mathrm{cm}$ mrad at the design operating condition. This figure is probably the same for all tl ree species.

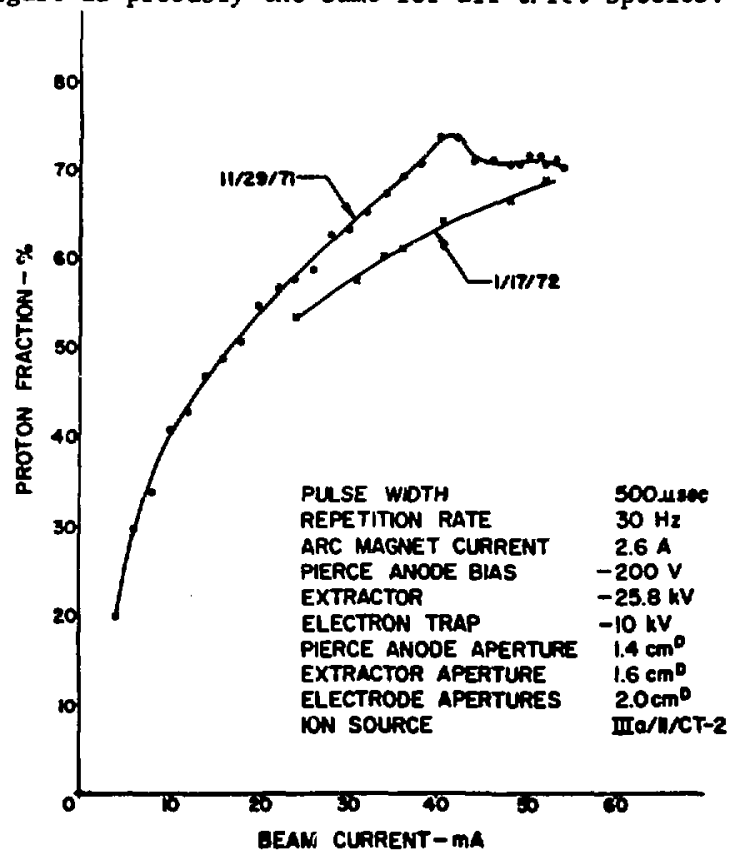

Fig. 3. Protor fraction measured as a function of total extracted current before and after pepper-pot tests.
Provision has been made in the design and construction of the source to allow for an increase in the cup depth. Spacers and spacer rings are pro$v$ ided for this purpose. These allow moving the body of the source back while the Pierce anode is kept in the same position relative to the extraction electrode of the column. This parameter was not explored in these experiments however, and thus its effect upon beam size and divergence is unknown.

\section{THE ACCELERATING COLIMN}

The $750-\mathrm{kV}$ accelerating column and associated vacuum system are shown in FIg. 4. The position of the ion source is also indicated.

The electrode configuration in the accelerating tube is shown more clearly in Fig. 5. All electrodes and other metal parts of the accelerating tube are of highly polished 6Al-4V titanium alloy. Pump-out holes are provided in the electrodes to keep the pressure $10 \mathrm{w}$, and they are staggered to reduce inline electron backstreaming. The electrode shapes are of Pierce geomatry and were determined from a solution of Laplaces equation ${ }^{2}$ to give zero radial acceleration to a uniform density, $50-\mathrm{mA}$ pure proton beam of $6.9-$ m radius. Contours for fabricating the electrodes are given in Table $I$. The last four electrodes are close approximations to the Pierce geometry, being straight for ease of fabrication, rather than slightly curved. The last two electrodes have larger apertures because of the exit aperture lens affect which, in theory, contributes a divergence of $1.09 \mathrm{mrad} / \mathrm{mm}$ of beam radius. Table II lists the axial position, diameter, and voltage for all electrodes.

The ninth electrode serves as an electron trap. It is biased at $-10 \mathrm{kV}$ to prevent electrons from entering the exit end and backstreaming up the accelerating tube. The electrode is thick to allow a large radius of curvature at the aperture to reduce the gradients where the equipotential lines curve around the electrode. With the trap biased at $-10 \mathrm{kV}$, the calculated axial potential barrier is $2.4 \mathrm{kV}$ for the simplified conditions assumed. The potential as a function of axial position is shown in F1g. 6 with the minimum occuring at the ninth electrode. Off axis, the potentjal barrier is larger, so that electrons must have an energy of at least $2.4 \mathrm{keV}$ to overcome the barrier.

The effectiveness of the barrier is shown by the low $x$-ray radiation in Fig. 7 . The component of 


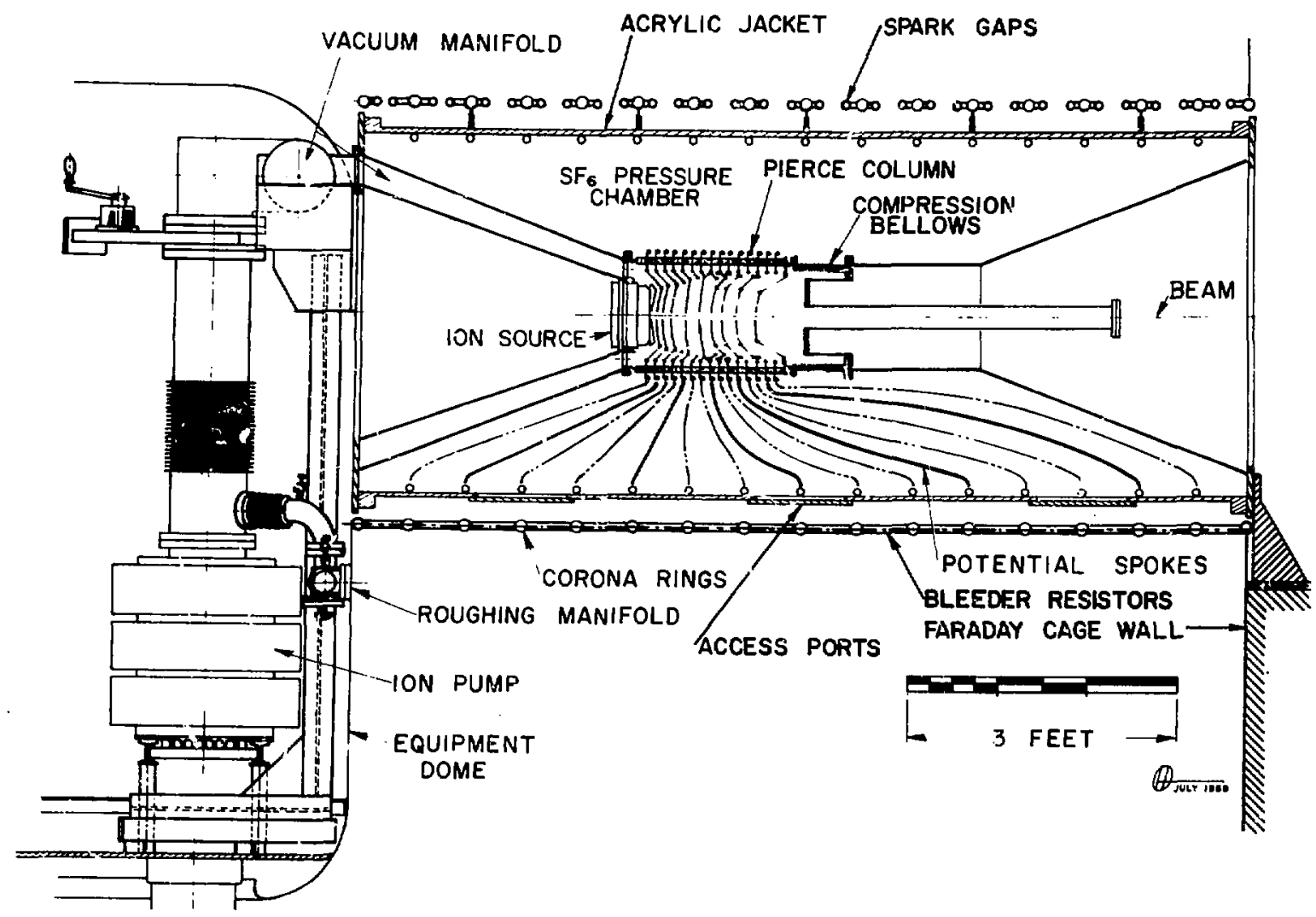

Fig. 4. The 750-kV acselerating columr, ion source and vacuum system.

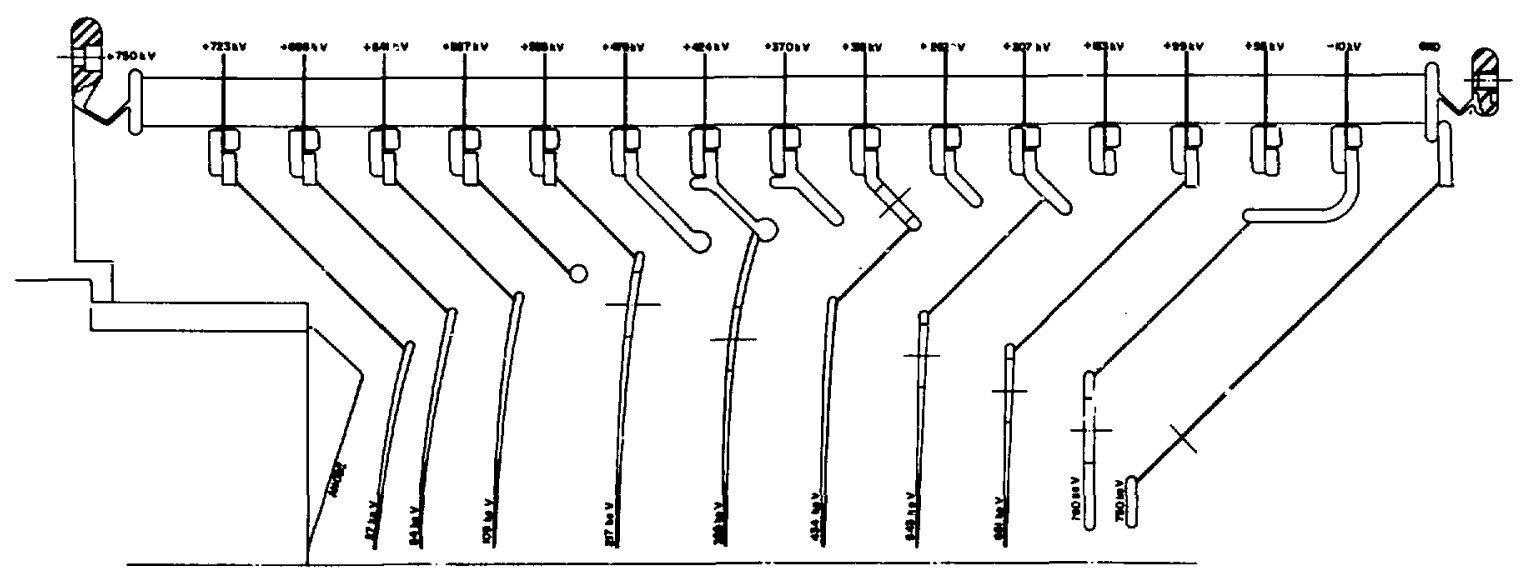

Fig. 5. Electrode configuration for the $750-\mathrm{kV}$ accelerating tube. Energy level is indicated by the nunber on the electrodes and applied voltages are indicated on the titanium washers. The thick electrode at $-10 \mathrm{kV}$ is an electron trap which stops electrons from entering and backstreaming up the accelerating tube. 
TABLE I

CONIUUR OF PIERCE ELECTRODES

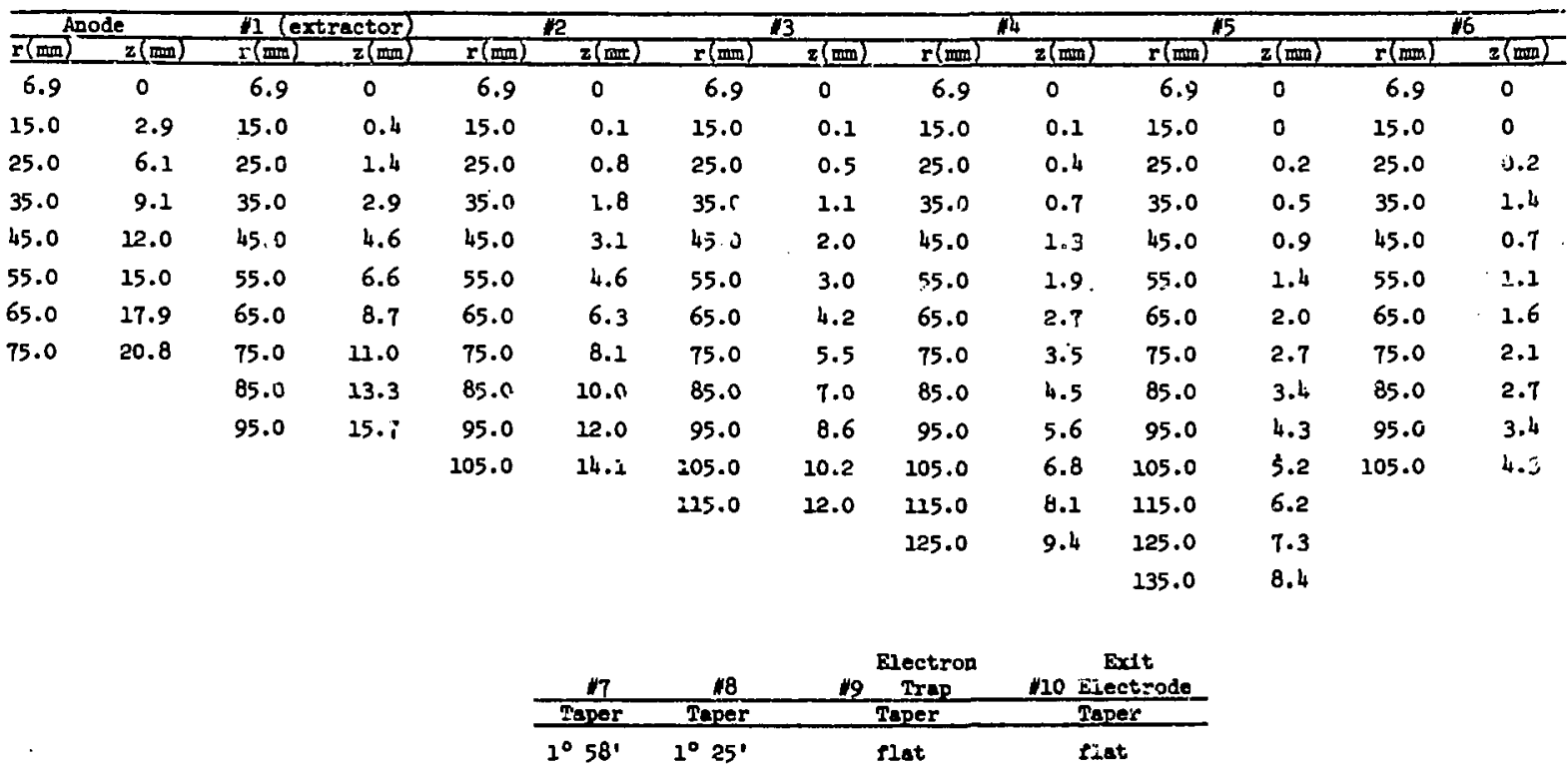

Note: Surfucs concour given for anode. Contour of electrode 11 1s center line velue and electrode sterts at $r$ - $8.0=$. Contours of electrodes $\boldsymbol{r}$ thru $\$ 8$ are centerline velues and electr- les at art at $r=10.0 \mathrm{~m}$.

TABLB II

PIBRCE ELSCTRODE GEOMETRY AND POTEITITALS

\begin{tabular}{|c|c|c|c|}
\hline Electrode & $\begin{array}{c}\text { Axtal } \\
\text { Position (cr) } \\
\end{array}$ & $\begin{array}{l}\text { Aperture } \\
\text { Dian (om) }\end{array}$ & $\begin{array}{l}\text { Potent1al } \\
(k V)\end{array}$ \\
\hline Anode & 0 & 1.38 & 750 \\
\hline 11 & 2.54 & 1.60 & 724 \\
\hline 12 & 4.28 & 2.00 & 696 \\
\hline 13 & 7.19 & 2.00 & 641 \\
\hline 14 & 12.09 & 2.00 & 533 \\
\hline 15 & 16.39 & 2.00 & +24 \\
\hline 16 & 20.34 & 2.00 & 316 \\
\hline 17 & 24.05 & 2.00 & 207 \\
\hline 18 & 27.57 & 2.00 & 99 \\
\hline 19 & 30.95 & 2.50 & -10 \\
\hline no & 32.59 & 2.70 & 0 \\
\hline
\end{tabular}

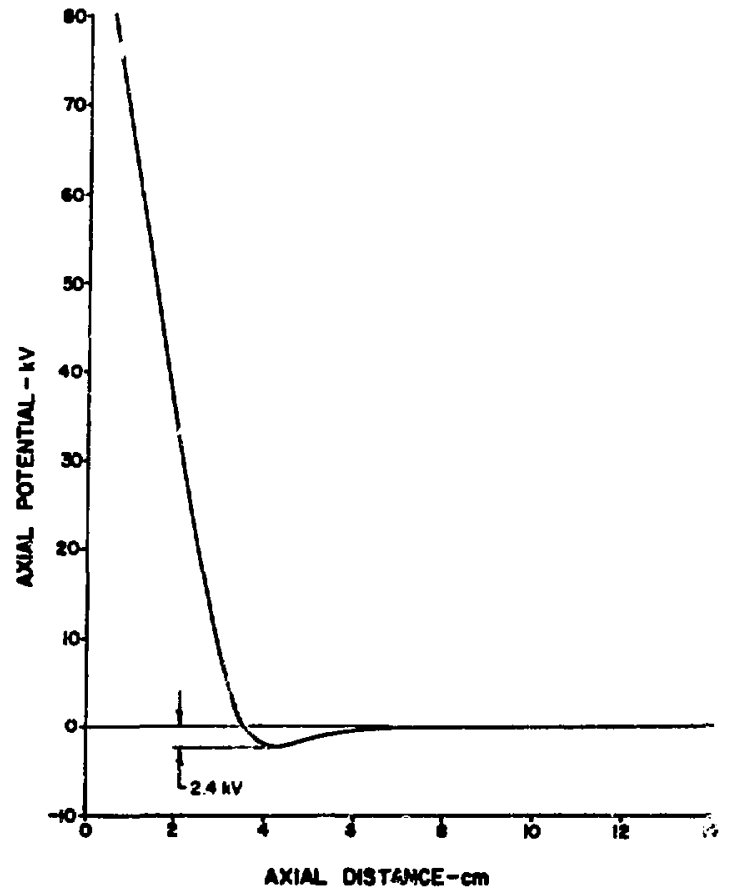

Fig. 6. Axial potential in the region of the elec. tron erap. With $-10 \mathrm{kV}$ applied to the trap, the axiel potential barriar is $2.4 \mathrm{kV}$. 


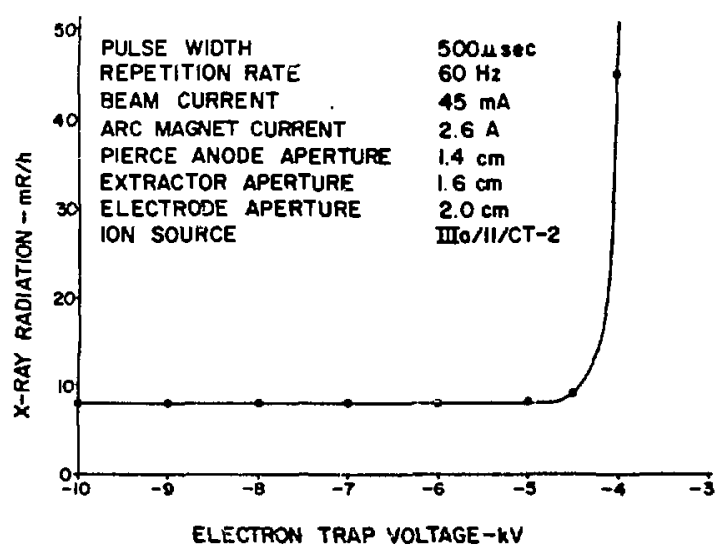

Fig. 7. X-ray radiation as a function of electron trap veltage. Electrons can overcone the potential barrier if the trap voltage is reduced below $-5 \mathrm{kV}$.

$x$-ray radiation produced by backstreaming electrons entering the tube and impacting the electrodes is negligible for trap voltages between $-10 \mathrm{kV}$ and -5 $\mathrm{kV}$. Above $-5 \mathrm{kV}$, the potential barrier is insufficient to stop the electrons, and the radiation rises sharply.

The extractor electrode, next to the Pierce anode, is connected to a separate power supply in the dome so extractor voltage can be set independently of column high voltage. This electrode is fitted with a replacerbie insert which reduces the aperture from 2.0 -to $1.6-\mathrm{cm}$ dian. The purpose of this insert is to intercept divergent ions at the extractor instead of letting them strike subsequent electrodes at much higher energy. When the beam strikes the titaniwn electrodes upstream from the electron trap, the secondary electrons produced are free to backstream up the tube, producing $x$ rays on impact. This $x$-ray radiation is shown as a function of total beam current in Fig. 8 for measurements made both before and after the pepper-pot tests. Radiation is low at the Pierce design current regzon ( $45 \mathrm{~mA}$ for a $70 \%$ proton fraction) because the beam space charge here is compensated by the Pierce geometry, so that the beam does not strike the electrodes. Radiation increases above the design current because the space charge becomes larger causing the core of the bean to diverge and strike the electrodes. Below the design current, measurements indicate that the radiation is caused by greatly expanded tails. Recent experiments based on theoretical analysis ${ }^{3}$ have shown that this radiation peak

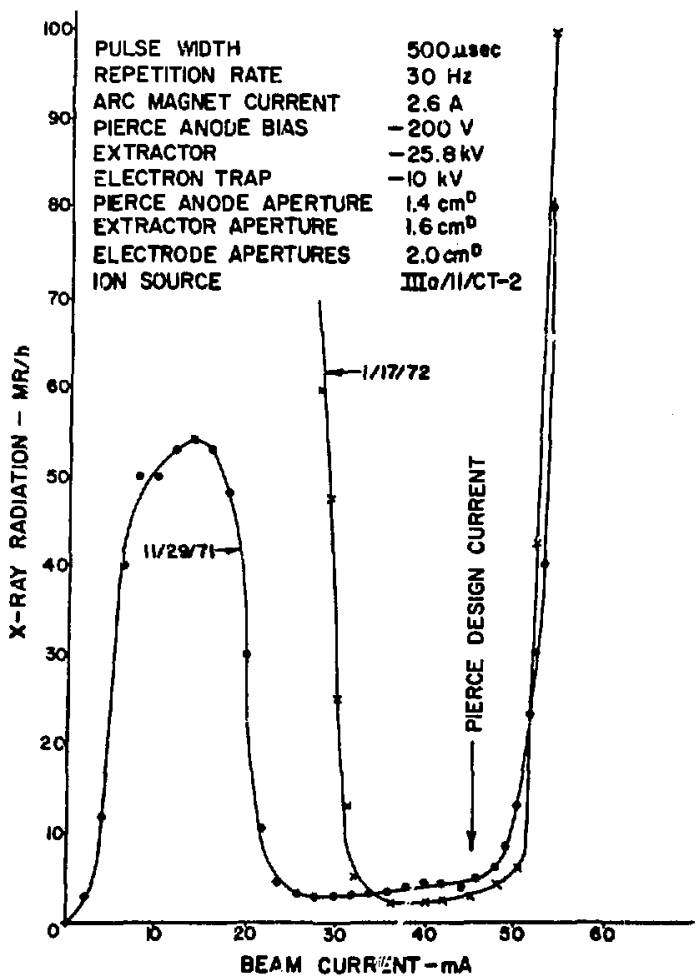

Fig. 8. X-ray radiation musured as a function of total extracted cirrent before and after pepper-pot tests.

can be eliminated by varying the extractor voltage parametrically with beam current. No change in extractor voltage is required near the Pierce design current.

In a measurement made after the pepper-pot tests, a substantial shift in the position of the lower end of the curve was noted. This shift can be seen in Fig. 8. It indicates that sonehow the tails were larger in size and were thus scraping the electrodes. Similar shifts have been seen before and are believed due to small variations in ion source parameters.

\section{PEPPER-POT APPARATUS}

A photograph of the assembled pepper-pot apparatus is shown in Fig. 9. The basic features are a titanium plate with an array of drilled holes, a quartz plate with ruled grid lines to match this array, and an observation window through which photographs are taken. The pepper pot was made of titanium to avoid the possibility of sputtering or evaporating a different material on the titanium electrodes in the column. 


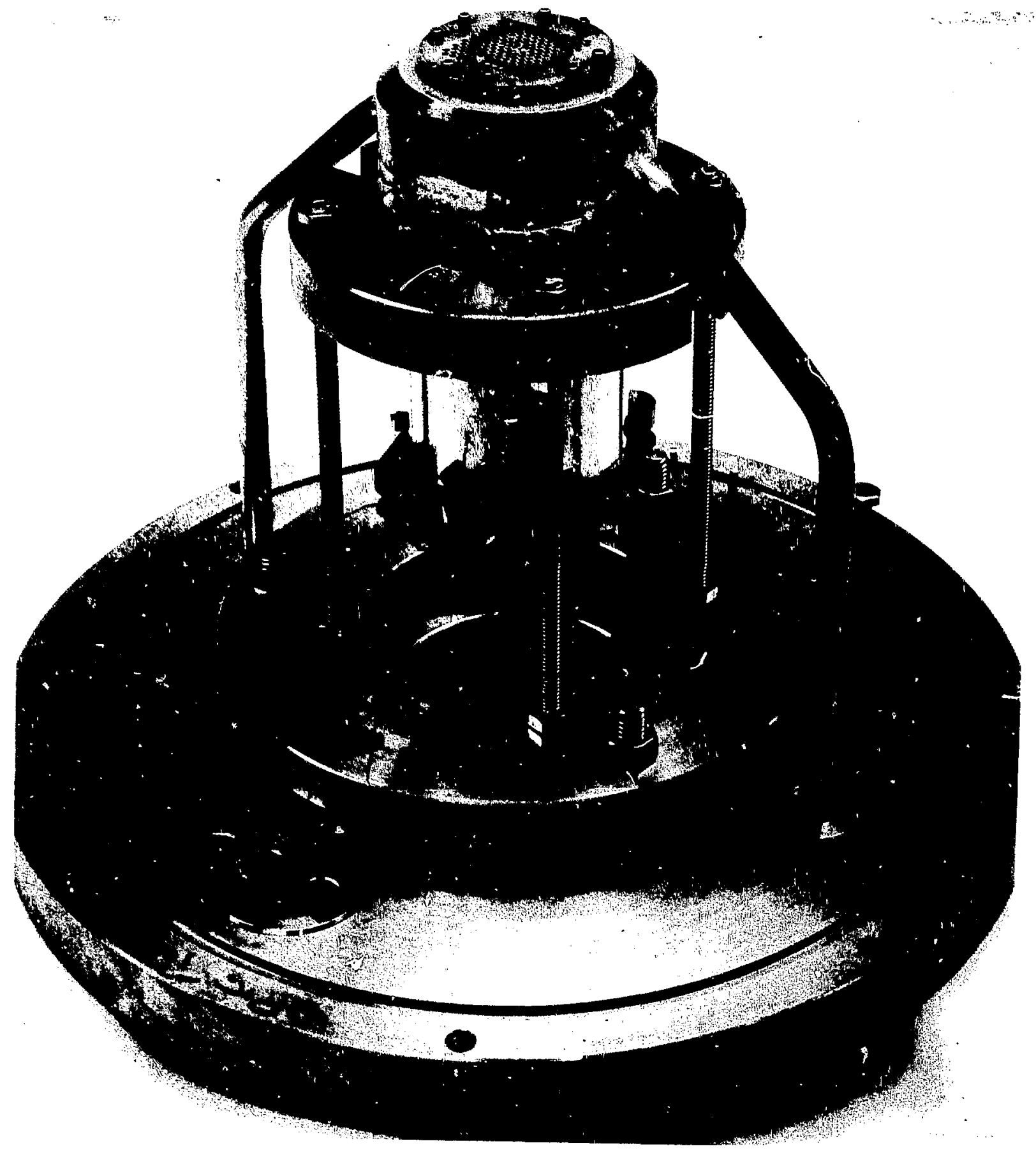

Fig. 9. The pepper-pot apparatus. 
Fig. 10 is a photograph of the titanium pepperpot plate taken from the heam side. The defining apertures, which are $0.005 \mathrm{~cm}$ in diameter, lie within the larger holes shown in this photograph. Information concerning the spacing of the equilaterial triangular array is given in Table III. By the time this photograph was taken, the central and immediately surrounding holes had heen melted shut. This melting also closed a 0.005 in. diam marking hole lying $0.020 \mathrm{in}$. to the left of the certer hole of the array. There is evidence that the melting was

TABLE III

PEPPEF POT

Equilateral Triangular Array

Horizontal spacing of the pepper-pot array and quartz plate grid

0.0938 in.

Vertical spacing of the pepper-pot array and quartz plate grid

0.0812 in.

Number of horizontal rows

15

Number of vertical columis

12 and 13

Diameter of defining apertures

$0.005 \mathrm{~cm}$

caused by failure of the modulator to turn off the beam at the and of the pulse, thereby greatly overheating the pepper pot.

As stated previously, the quartz plate had grid lines ruled on it on the side on which the beam strikes. The spacings of these ruled lines correspond to the base and altitude of the equilateral triangles of the pepper-pot pattern. A set of diag-

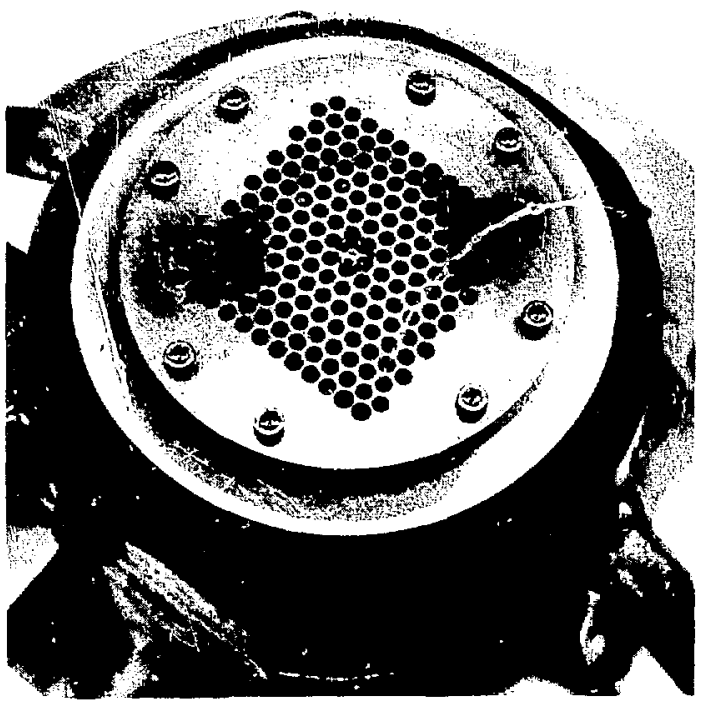

Fig. 10. The titanium pepper-pot plate. onal dotted lines was used to mark the center of the grid. The lines wer illuminated by a lamp inserted in a hole drilled in one corner of the plate.

For these experiments, the apparatus was installed on the accelerating column compression bellows flange as shown in Fig. 11. The axial positions of the pepper-pot elements with respect to the source and column are given in Table IV. An alignment measurement of the pepper pot with respect to the center iine of the column was also made. A jig transit was aligned on the anode aperture and a lucite

TABLE IV

AXIAL POSITION OF PEPPER-POT ELEMENTS

\begin{tabular}{lc}
\hline \multicolumn{1}{c}{ Item } & Axial Fosition $(\mathrm{cm})$ \\
\hline Pierce anode & -32.59 \\
Extractor & -30.05 \\
Center plane of $\# E$ electrode & -5.02 \\
Center plane of tiap electrode & -1.64 \\
Exit side of last electrode & 0.00 \\
Defining plane of pepper-pot holes & +12.80 \\
Beam side of quartz plate & +25.13 \\
Outside surface of viewing window & +35.6
\end{tabular}

target installed in the aperture of the tenth electrode. The pepper pot was found to be aligned vertically, but to lie 0.051 in. to the right, looking downstrean, of the column axis.

To enable an accurate measurement of beam current striking the pepper pot and to determine the neutralization effect, it was necessary to bias the pupper-pot plate. For these tests, the plate was connected through a $150-V$ battery and a 100- $\Omega$ resistor to ground so as to bias it at $+150 \mathrm{~V}$ with respect to the surrounding metal parts. The beam current produced a voltage signal across the $100-\Omega$ resistor which was observed on an oscilloscope. The wire from the pepper pot to the biasing battery passed through a current transformer which also produced a voltage signal proportional to beam current. These two beam current measurements were observed to agree to within $5 \%$ throughout the pepper-pot measurements.

Current measured as a function of pepper-pot bias voltage is shown in Fig. 12. The curves become very flat ahove $120 \mathrm{~V}$, indicating that almost all of the electrons produced at the plate were captured by the plate. Further evidence of this was provided 


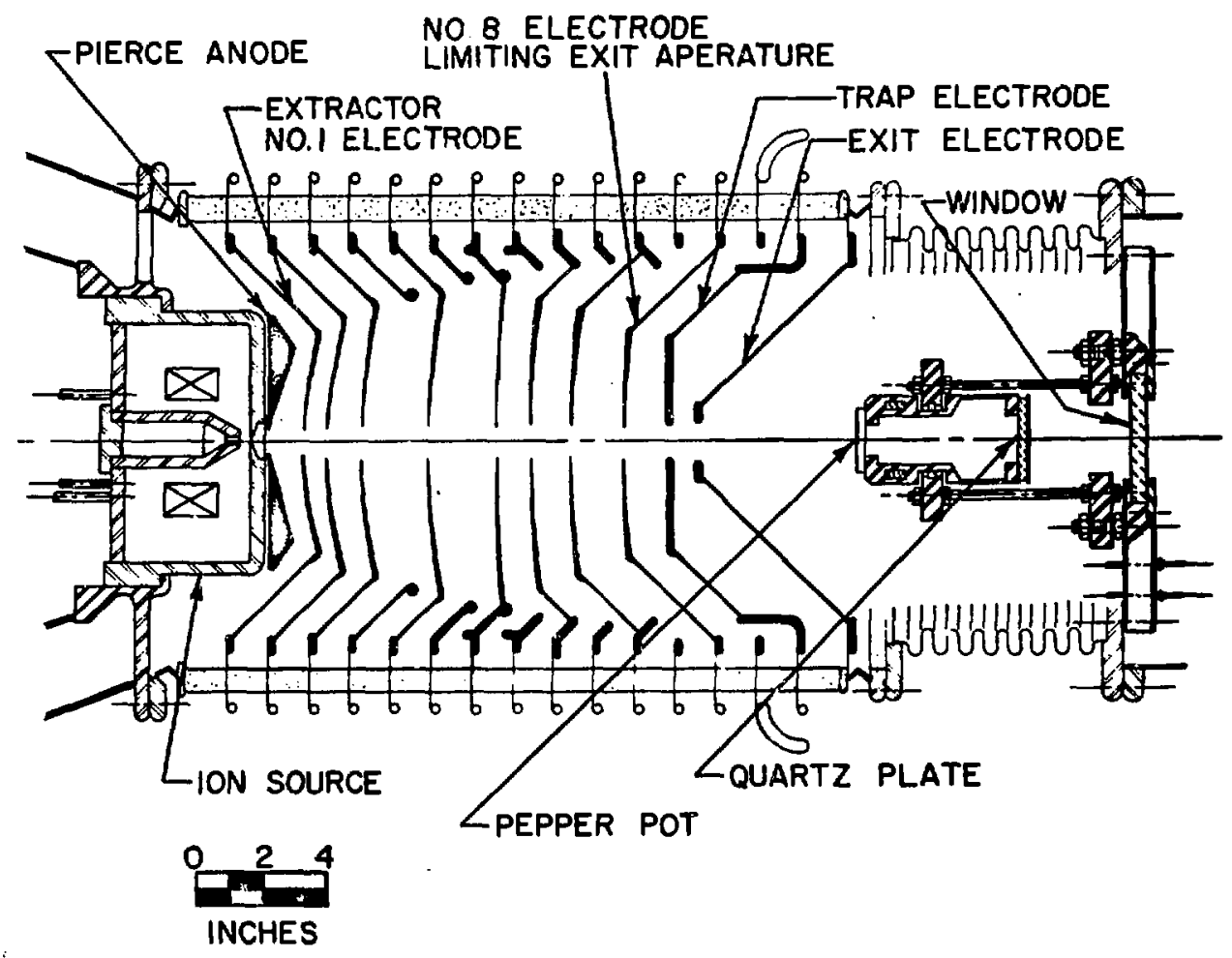

Fig. 11. The ion source, accelerating colunn, and pepper-pot apparatus.

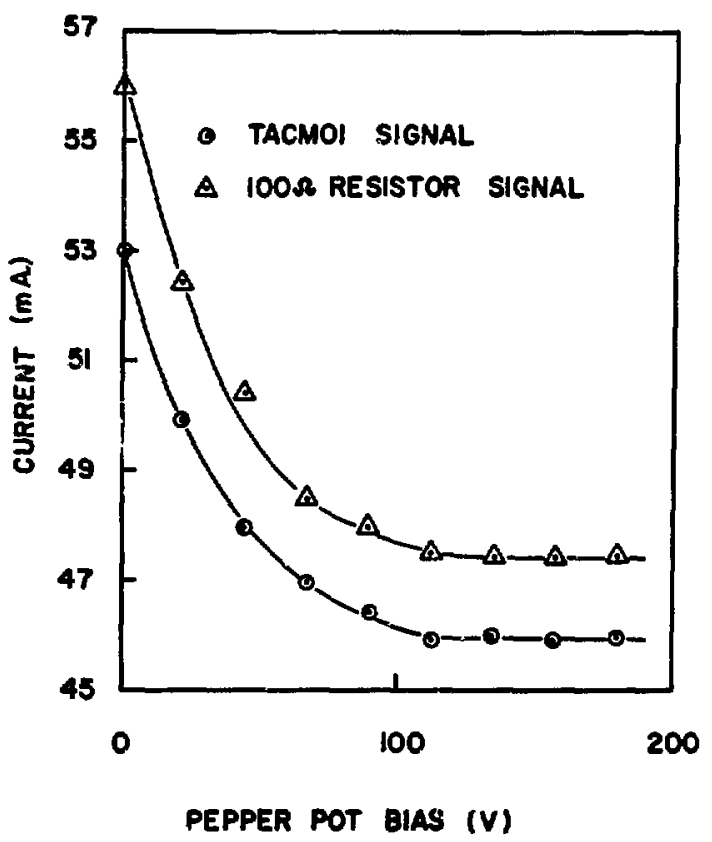

Fig. 12. Current measured versus pepper-pot bias.

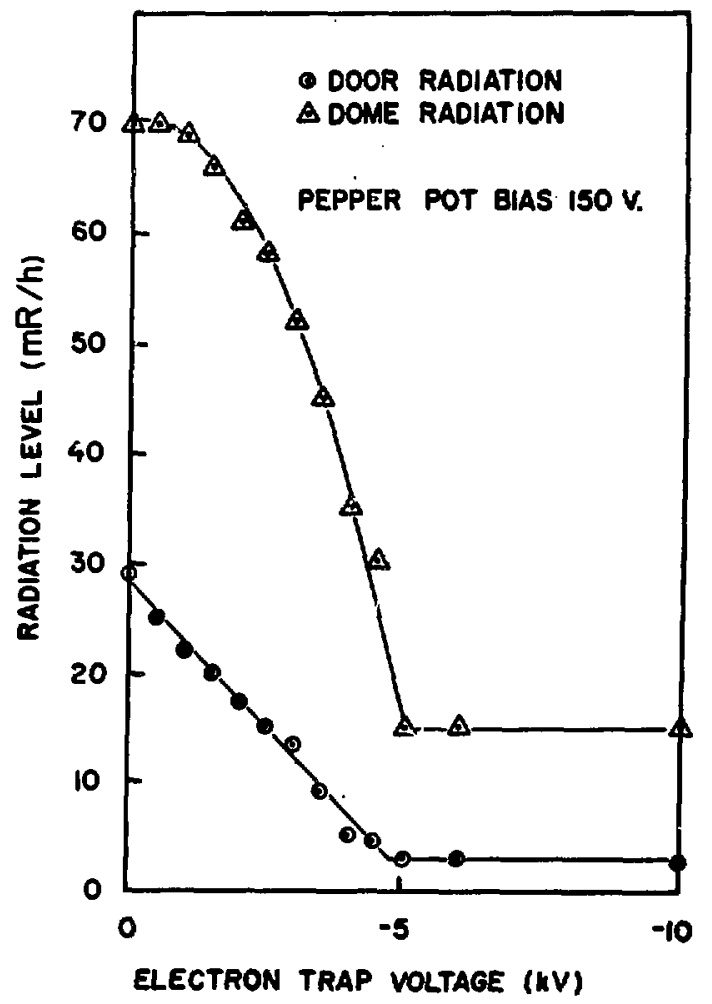

Fig. 13. Radiation as a function of electron trap voltage. 
later in the experiments when the electron trap voltage was reduced from $-10 \mathrm{kV}$ to zero potential. The effect upon radiation produced is shown in Fig. 13. This result can be compared with that shown in Fig. 7, for which no biasing to remove electrons from the beam was done. Although different duty factors were involved, this comparison provides striking evidence of a high electron capture efficiency. The pepper-pot plate bias used in the tests and to produce Fig. 13 was $150 \mathrm{~V}$. The $2 \mathrm{~mA}$ difference between the two determinations of the same current shown in Fig. 12 is probably due to improper gain of the current monitor amplifier. This discrepancy was removed just after the " $A$ " series of pepper-pot photographs were taken. The current monitor and the 100$\Omega$ resistor read identically for the remainder of the pepper-pot pictures.

The reentrant can of the column proved to be a difficult place to take photographs. An elaborate mechanical sliding track and locating pin arrangement was made so that the camera could slide out three or four feet for loading and then be repositioned to within a few mils. The $4 \times 5$ camera was critically focused with polaroid film and a micrometer lead screw. v. QUARTZ VIEWING SCRFFN MEASUREMENTS

A measurement of bean size near the exit of the column was made using a quartz plate viewing scroen assembly installed onto the reentrant can at the exit of the accelerating tube as shown in Fig. 14. The quartz plate was viewed with a closed TV system, and photographs were taken of beam cross sectivns directly from the TV screen. The quartz screen was located $16 \mathrm{in}$. from the last electrode of the accelerating tube. A graticule was scribed on the quartz plate with $1-\mathrm{cm}$ spacing.

The quartz plate was aluminized in order to drain charge from the viewing screen. This coating, however, was quickly sputtered away in the central region of the screen; some sparking was then observed on the quart $z$, but observations of the bean could still be made. Provision was made to bias the housing and quartz screen, but no difference in beam cross sections was observed when bias voltage was applied. The quartz plate may have been selfbiasing after the aluminum coating was rewoved. In any event, the secondary electrons emitted by the quartz screen did not affect the bean measurenents. The ion current to the quartz place assembly was measured by passing the grounding wire from this

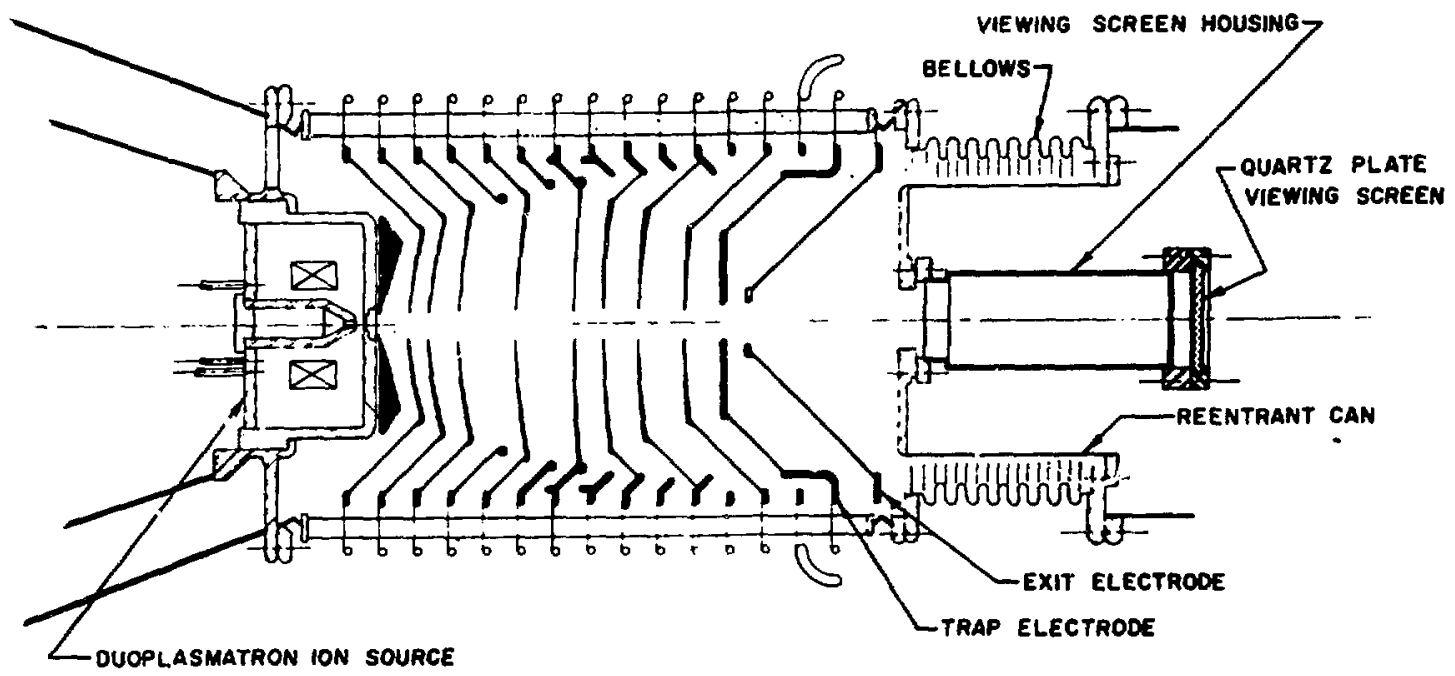

$$
\text { [-iv-1 }
$$

CENTIMETERS

Fig. 14. The ion source, accelerating colun, and quartz plate ussembly. 
assembly through a beam current monitor and observing the current pulse from this transformer.

Photographs were taken oi beam sections for three arc magnet currents over a range of extracted ion currents from 10-46 mA. Figures 15-17 show the results for a 20 usec pulse width. Data on the beam size were obtained hy visual interpretation of these pictures: results are plotted in Fig. 18.

In general, the heam size grows with increasing current extracted from the ion source. At $40 \mathrm{~mA}$, the heam size appears to approach some limit, and thereafter increases only slightly. At lower beam currents, the beam size becones smaller as the arc magnet current is increased. However, near the standard operating current, there is little apparent variation in heam size with arc magnet current. At an operating current of $46 \mathrm{~mA}$, a heam size of 3.50 $\mathrm{cm}$ was measured on the quartz screen.

Photographs were also taken of beams with longer pulse lengths. The pictures st own in Figs. 19-21 were taken of a 100-usec pulse length heam using the three previously given arc magnet current settings. The beam sizes are essentially the same as those obtained at 20 usec. The hollow siructures and rings seen at lower currents are believed in large part due to beam heating effects in the quartz plate. These heating effects result in a decreased light output. Other measurements at the column and along the beam line have shown some evidence for hollow beam structures, but not to the extent suggested hy these photographs. The microdensitometer and vidicon data presented later in this report are in suhstantial disagreement on this question. The heam heating effect is discussed quantitatively in the Appendix.

Another series of pictures, shown in Figs. 22 and 23 , was taken at still a longer pulse length (180 usec) to stidy growth of the halo, or tails, as a function of extracted current. At low currents, a smaller central beam spot with a large halo is observed. At $10 \mathrm{~mA}$, the beam core is $0.28 \mathrm{~cm}$ in diameter, and it is surrounded óy a halo $2.7 \mathrm{~cm}$ in diameter. As the beam current is increased the beam spot and halo grow. At apnroximately $20 \mathrm{~mA}$, the halo reaches a maximum size of $4.5-\mathrm{cm}-\mathrm{diam}$ and from that point on decreases in size with increasing current.

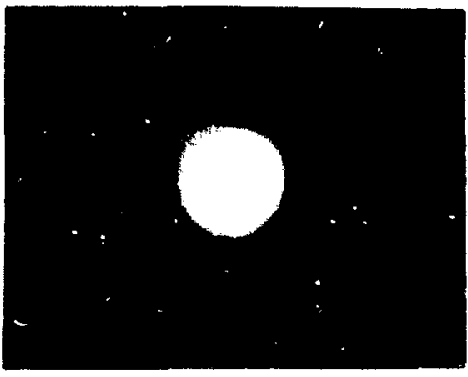

$10 \mathrm{~mA}$

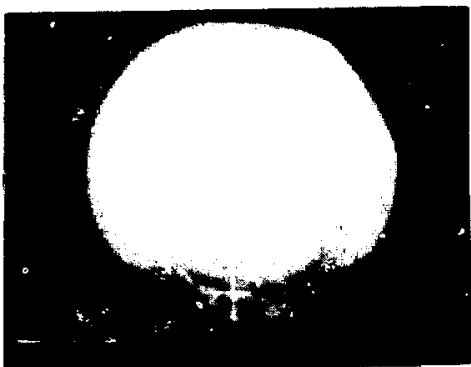

$40 \mathrm{~mA}$

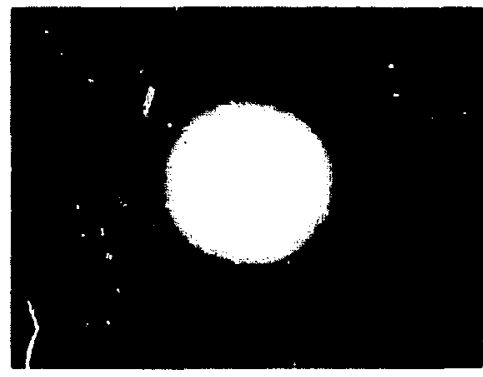

$20 \mathrm{~mA}$

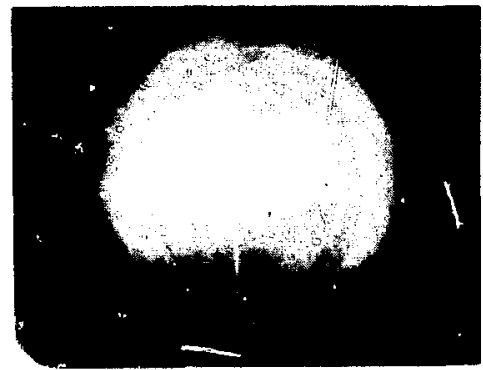

$44 \mathrm{~mA}$

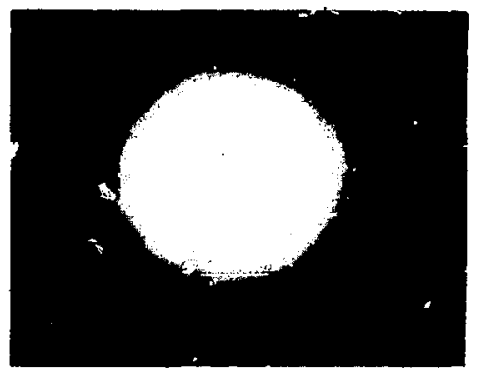

$30 \mathrm{~mA}$

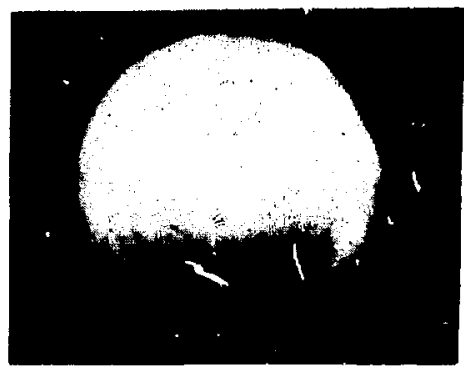

$46 \mathrm{~mA}$

Fig. 15. Bean cross section with arc magnet current $1.5 n A$ and pulse length 20 usec. 


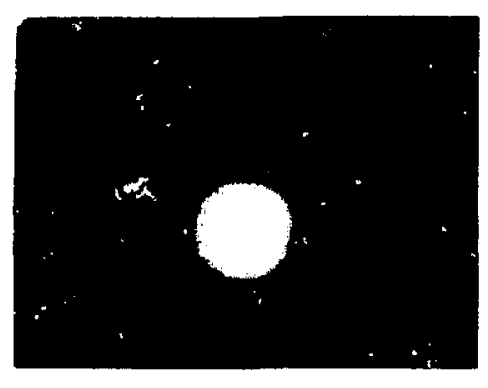

$10 \mathrm{~mA}$

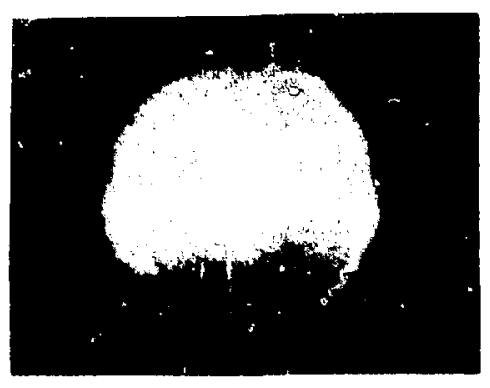

$40 \mathrm{~mA}$

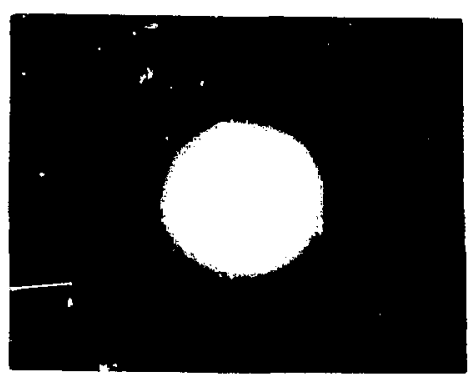

$20 \mathrm{~mA}$

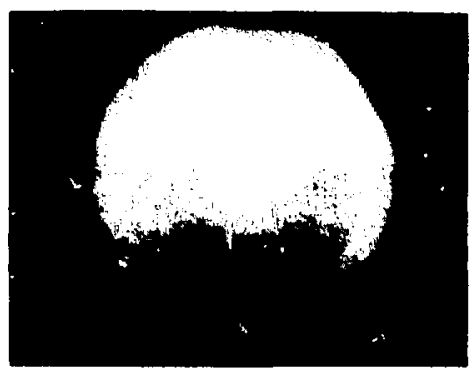

$44 \mathrm{~mA}$

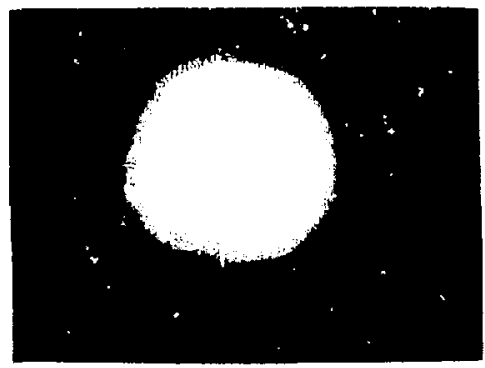

$30 \mathrm{~mA}$

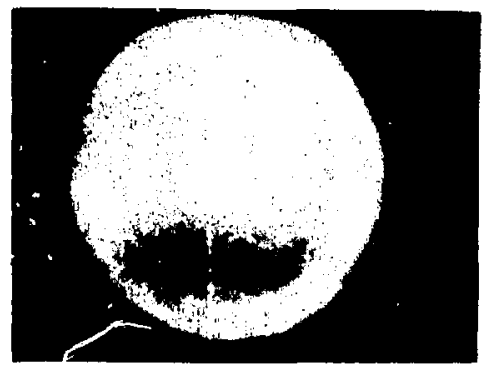

$46 \mathrm{~mA}$

Fig. 16. Beam cross section with arc mapnet curment $1.75 \mathrm{~A}$ and pulse length 20 usec.

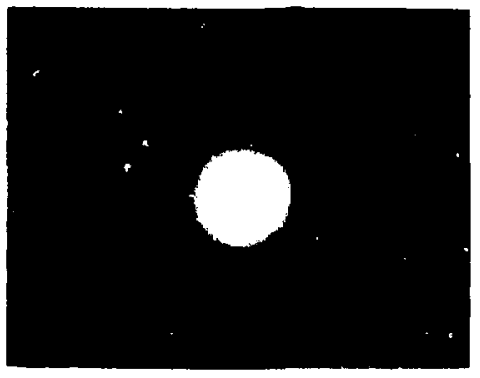

$10 \mathrm{~mA}$

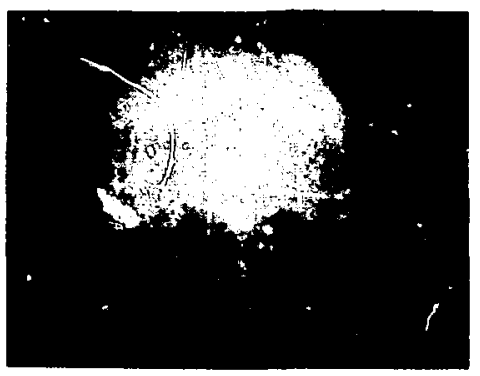

$40 \mathrm{~mA}$

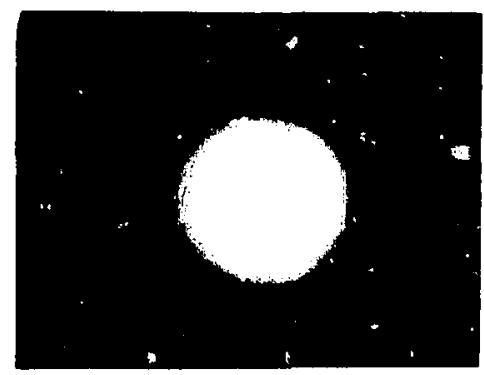

$20 \mathrm{~mA}$

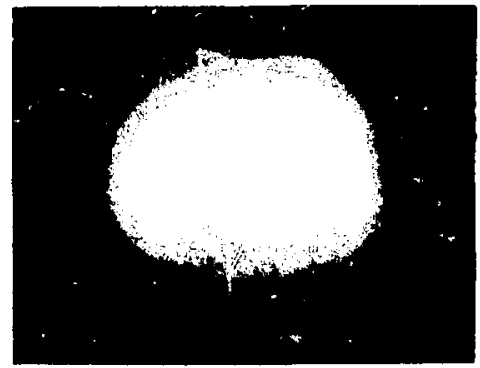

$44 \mathrm{~mA}$

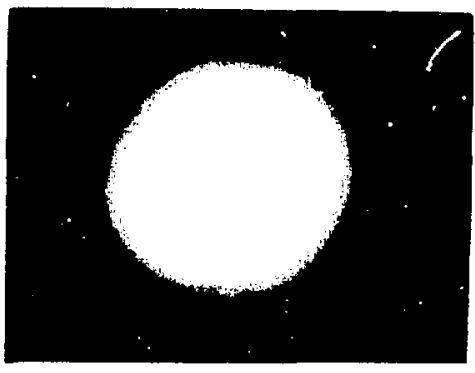

$30 \mathrm{~mA}$

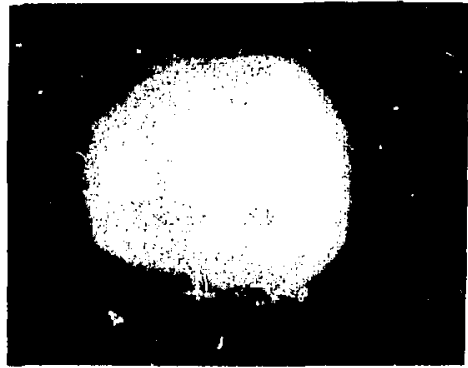

$46 \mathrm{~mA}$

Fig. 17. Beam cross section with arc magnet current 2.60 A and pulse length 20 usec. 


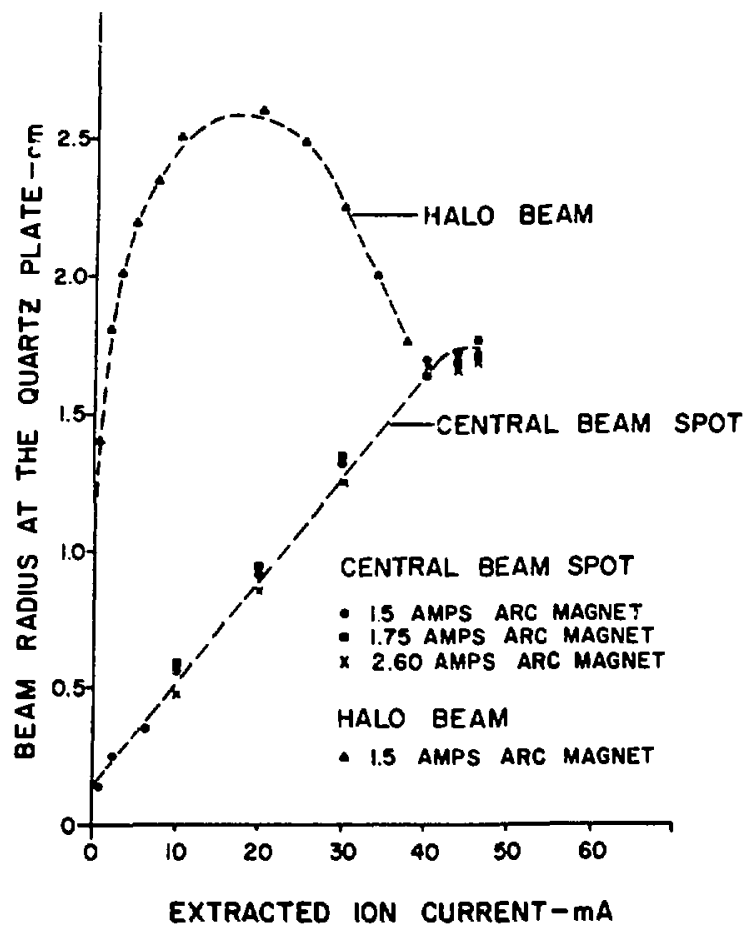

Fig. 18. Bean size versus extracted ion current.
At $40 \mathrm{~mA}$, the halo disapnears into the central beam spot. The peak near $20 \mathrm{~mA}$ agrees with the maximum observed in the $x$-ray background from the column at this current and with observations of the current picked up on the column electrodes.

The halo is also ohserved in bean cross sections at three viewing screens on the bean transport line. Figure 24 shows bean cross sections for Beam 6 . We note that the amount of halo decreases with increasing current but is still present in the heam even at higher currents. Although the tails merge in coordinate space with the main hody of the heam at the quartz plate, they represent a much different mase-space, and thus will reappear distinctly as halo at other points in the beam tronsport line.

\section{INTFNSITY PROFII.F. MEASIIRFMFNTS}

Two different approaches were used to measure the variation in intensity across the beam. Both relied on interpretation of the light produced by heom striking the quartz plate of $a$ pepper-pot apparatus .

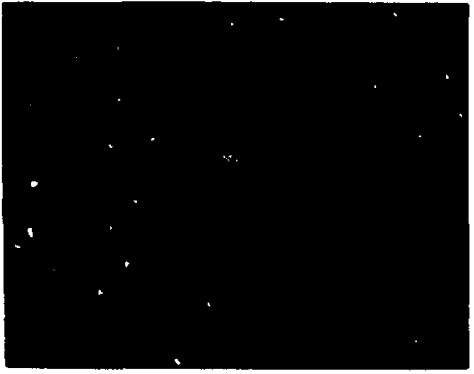

$10 \mathrm{~mA}$

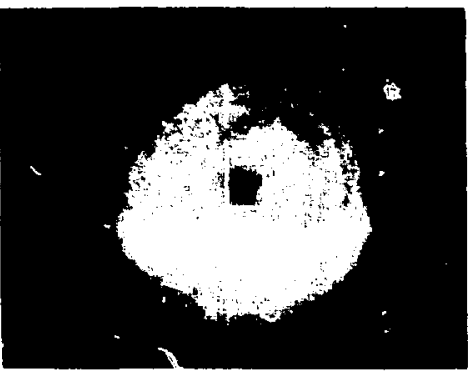

$40 \mathrm{~mA}$

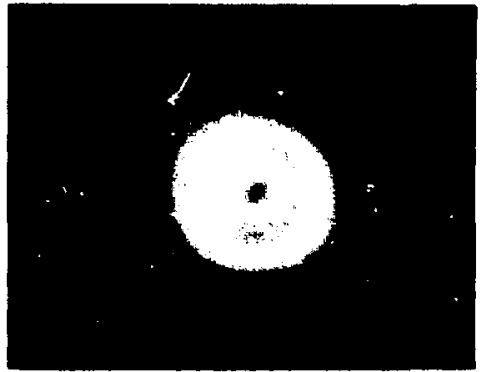

$20 \mathrm{~mA}$

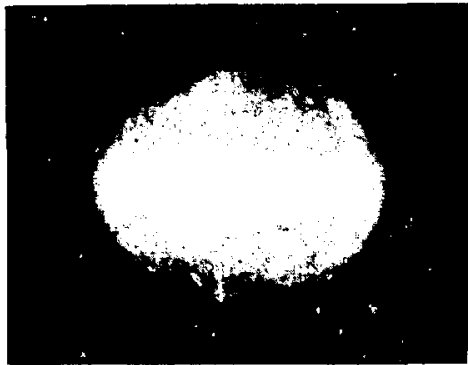

$44 \mathrm{~mA}$

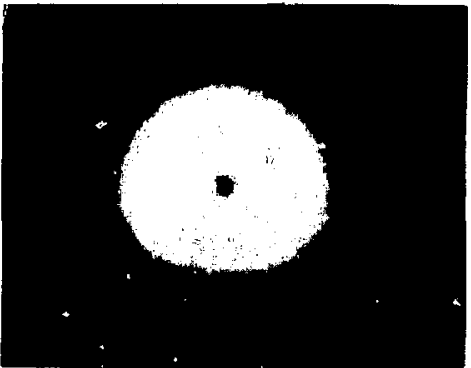

$30 \mathrm{~mA}$

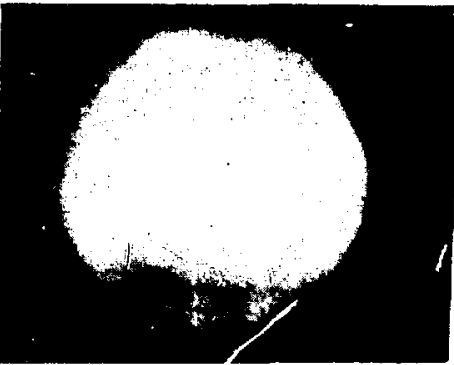

$46 \mathrm{~mA}$

Fig. 19. Beam cross section with arc magnet current 1.50 A and pulse length 100 usec. 


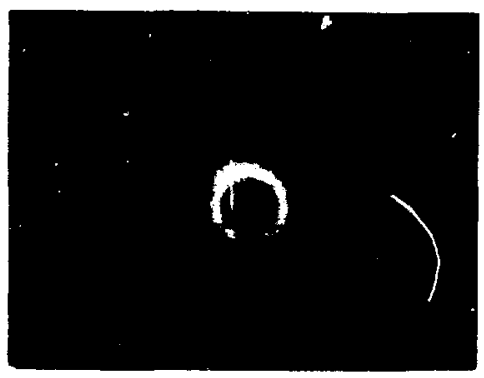

$10 \mathrm{~mA}$

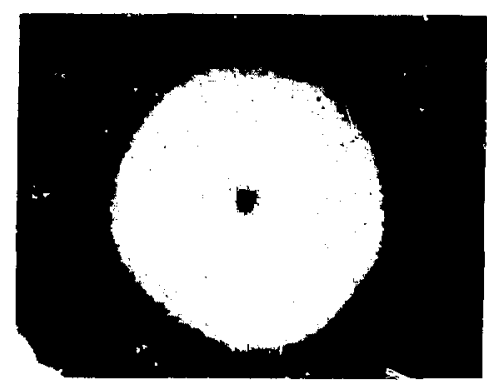

$40 \mathrm{~mA}$

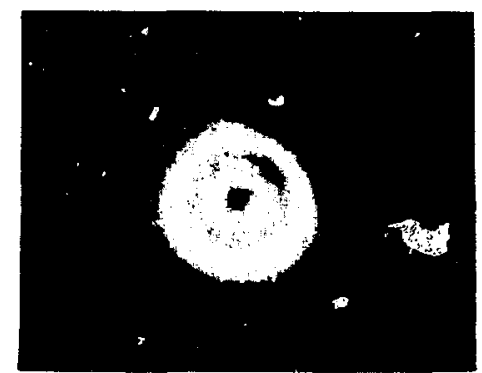

$20 \mathrm{~mA}$

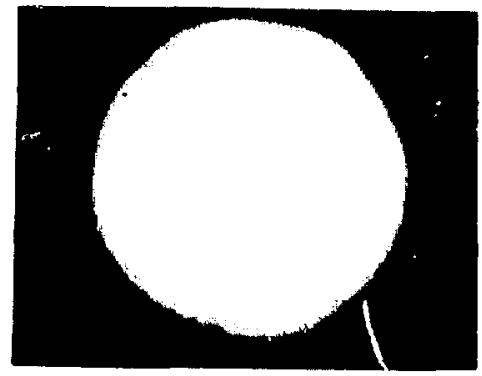

$44 \mathrm{~mA}$

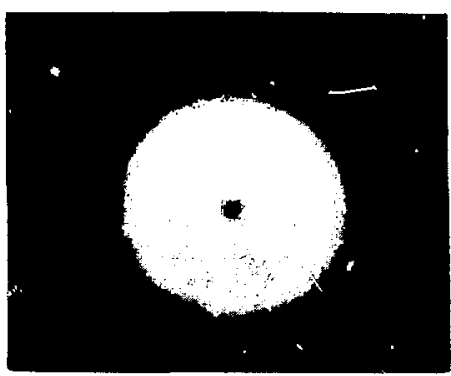

$30 \mathrm{~mA}$

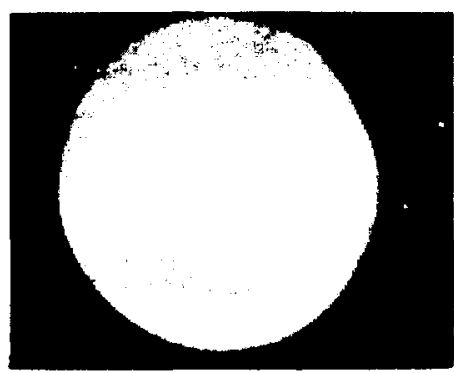

$46 \mathrm{~mA}$

Fig. 20. Beam cross section wtih arc magnet current $1.75 A$ and pulse length $100 \mu \mathrm{sec}$.

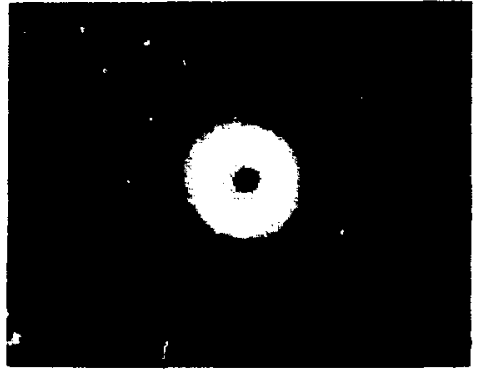

$10 \mathrm{~mA}$

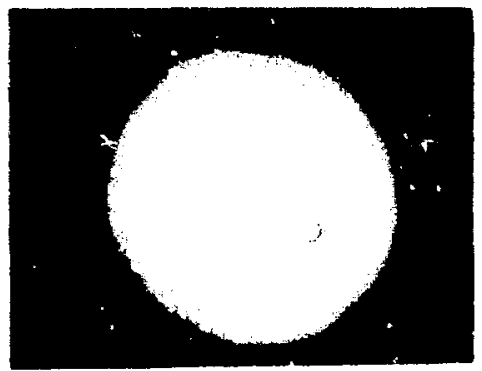

$40 \mathrm{~mA}$

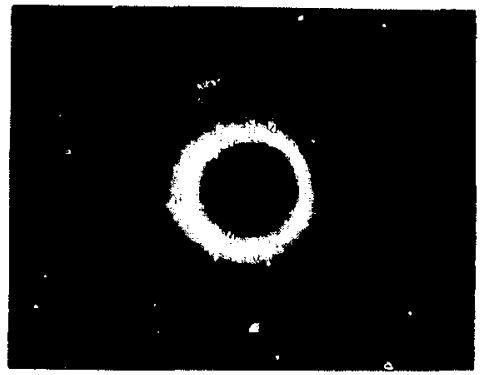

$20 \mathrm{~mA}$

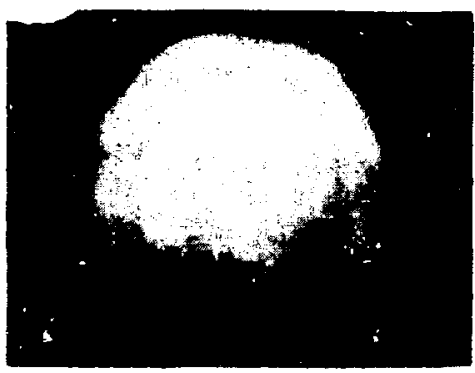

$44 \mathrm{~mA}$

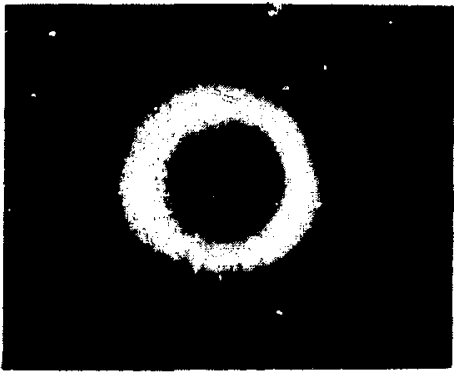

$30 \mathrm{~mA}$

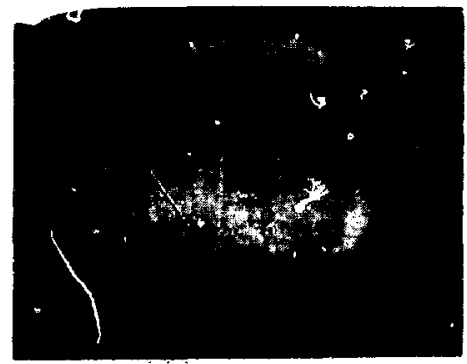

$46 \mathrm{~mA}$

Fig. 21. Beam cross section with arc magnet current $2.60 A$ and pulse length 1 nn usec. 


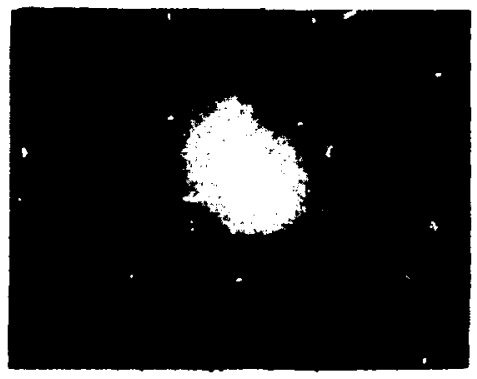

$2 m A$

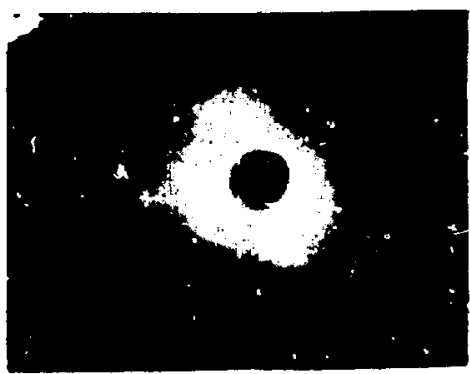

$10 \mathrm{~mA}$

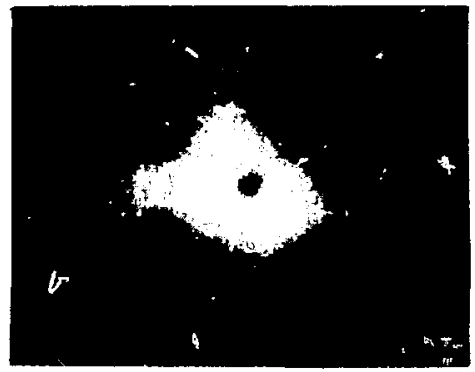

$5 \mathrm{~mA}$

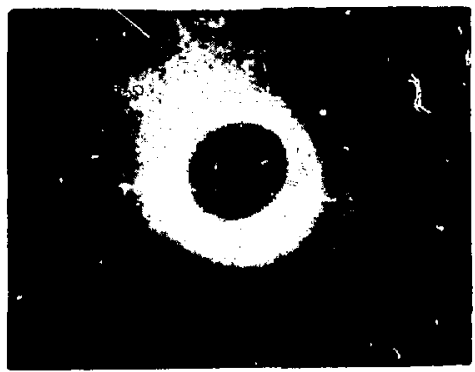

$20 \mathrm{~mA}$

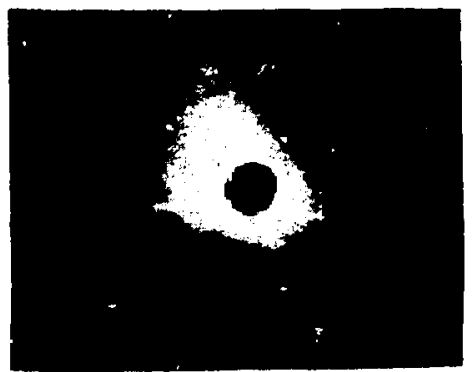

$8 \mathrm{~mA}$

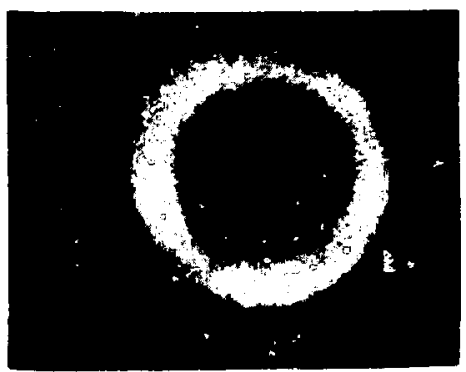

$29 \mathrm{~mA}$

Fig. 22. Bean cross section with arc magnet current $1.50 \mathrm{~A}$ and pulse length 180 usec.

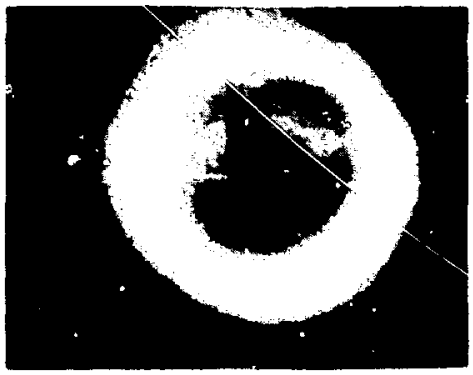

$34 \mathrm{~mA}$

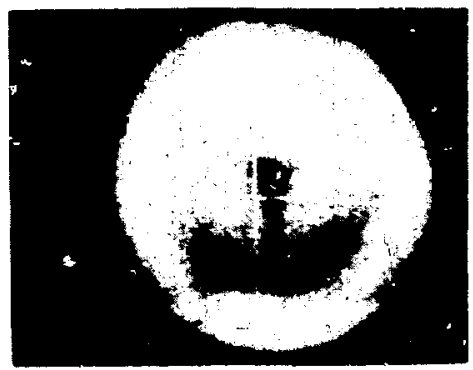

$42 \mathrm{~mA}$

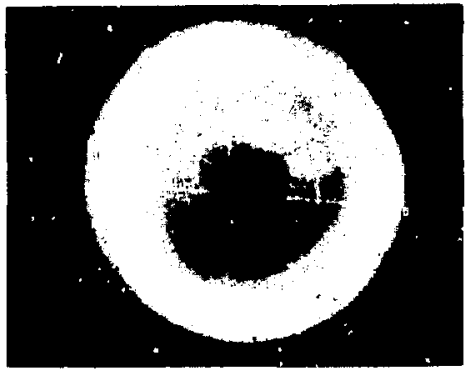

$38 \mathrm{~mA}$

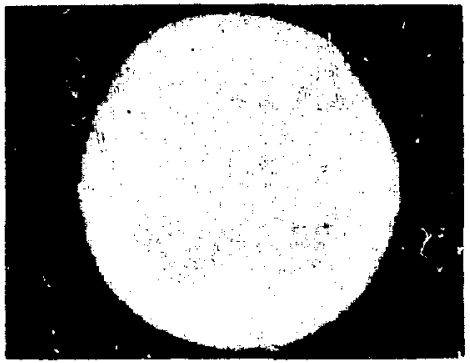

$43 \mathrm{~mA}$

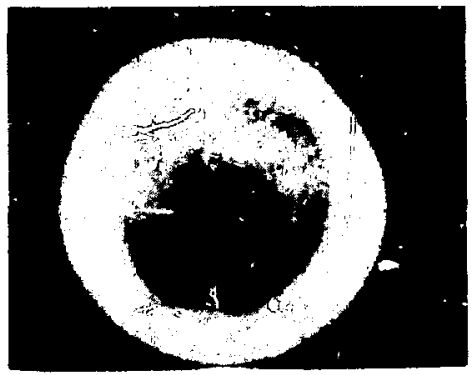

$40 \mathrm{~mA}$

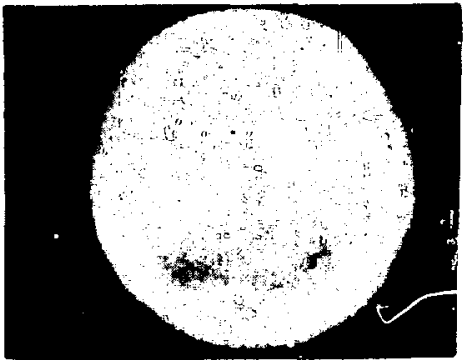

$44 \mathrm{~mA}$

F1g. 23. Bean cross section weih are magnet current $1 \ldots$... and pulse length 180 usec. 

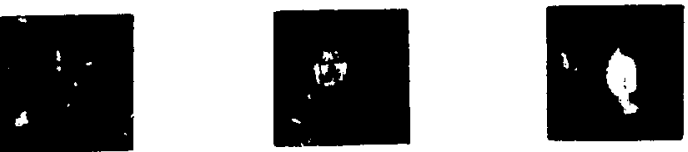

$28 \mathrm{~mA}$
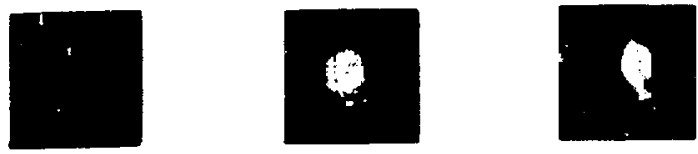

$32 \mathrm{~mA}$
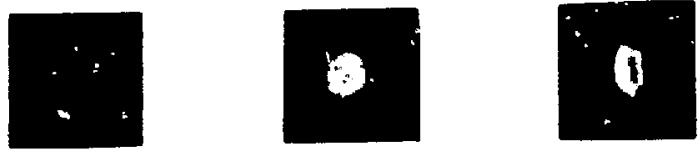

$36 \mathrm{~mA}$
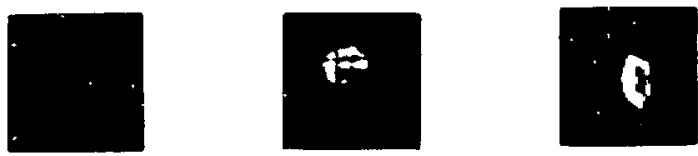

$40 \mathrm{~mA}$
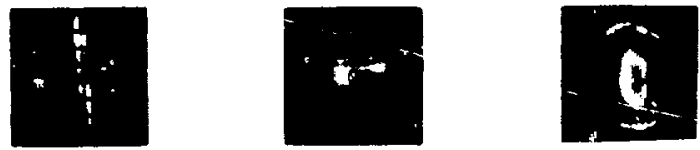

$44 \mathrm{~mA}$
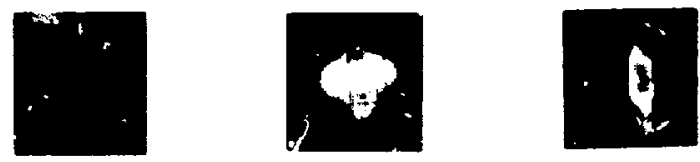

$48 \mathrm{~mA}$

Fig. 24. Bean cross sections for benn 6 .

The first approsch involved use of a TV vidicon device. 4 For these measurements a sing! 2-row pepFer pot was installed which had a hole separation of $0.234 \mathrm{~cm}$ and hole size of $0.005 \mathrm{in}$. The output from a single scan line from the pepper-pot imape on a TV vidicon was obtained by using a delayed CRO (cathode ray oscilloscope) sweep of the proper length. The delay time, relative to the frame reference pulse, was adjusied to select the scan line running through a diametral horizontal row of pepper- pot dots. The position of the vidicon was adjusted vertically with a micrometer screw so that the selected scan line ran through the centers of all the dots.

A neutral step wedge was used with a proper light source to relate the CRO amplitudes to relative light intensity. The relationship is shown in Fig. 25, and appears roughly linear. However, there is as ye: no clear way to relate beam intensity to light intensity on the quartz screen. Therefore, work will continue on the analysis of these data.

Six of the intensity profiles are shown in Fig. 26. These were taken near the operating point for several different arc nagnet currents. As is apparent from these photographs, the center-most hole had melted shut. However, the adjacent holes were not affected.

As can be seen by a comparison of the three photographs taken at $40 \mathrm{~mA}$, arc magnet current appears to have a strong effect on the radial intensity of the bean. (It will be shown later that the phase space envelopes are hasically unaffected by this parameter.) As the two photographs taken at $44 \mathrm{niA}$ indicate, increasing the extracted ion current appear: to have the effect of spreading the beam. The last photograph in Fig. 26 was taken at $48 \mathrm{~mA}$, and at a different scale than the other 5 photographs.

The second approach to this problem involved reduction of the photographs taken for the phase space analysis. Intensity information on these

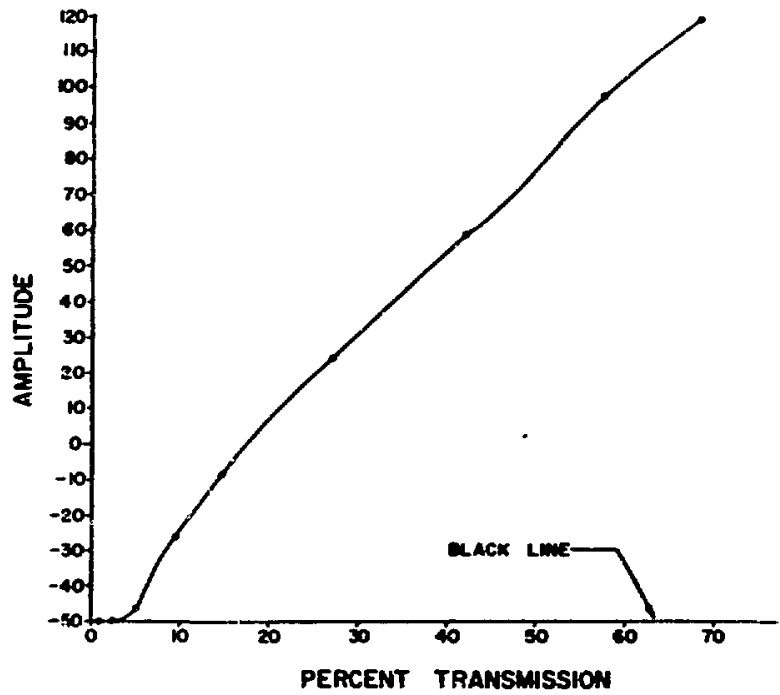

Fig. 25. Vidicor, normalization curre. 

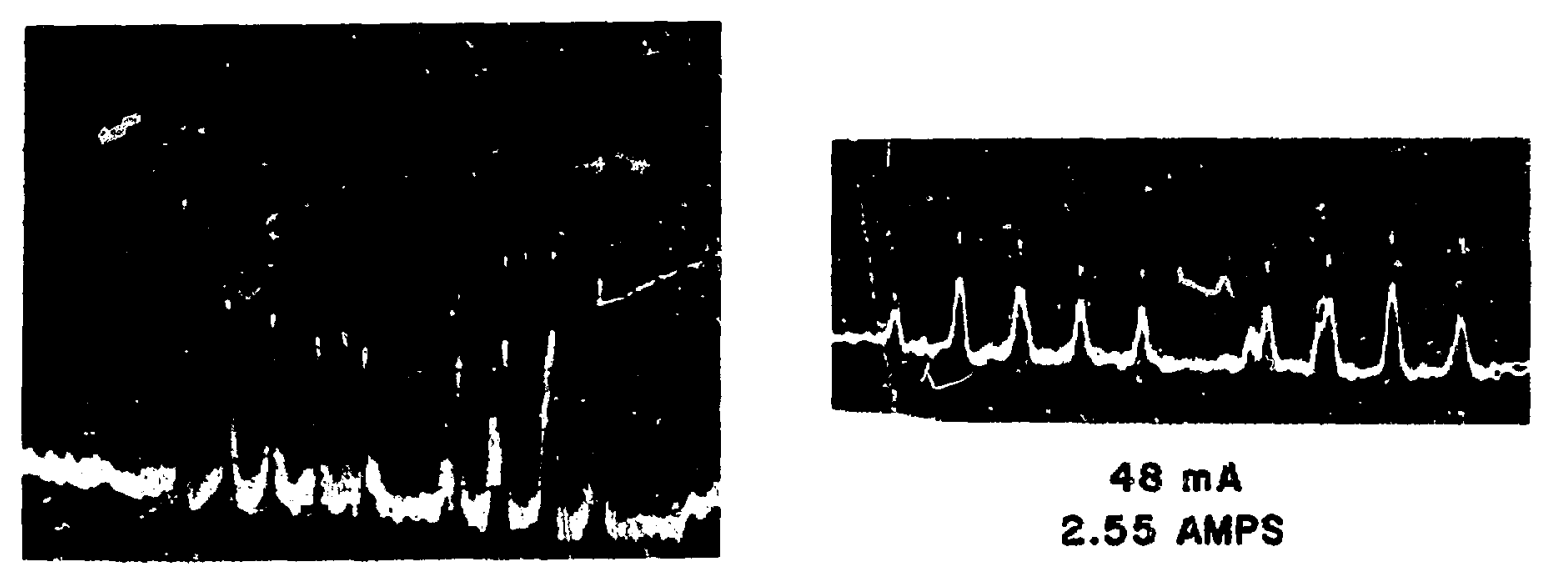

$40 \mathrm{~mA}$

\subsection{AMPS}

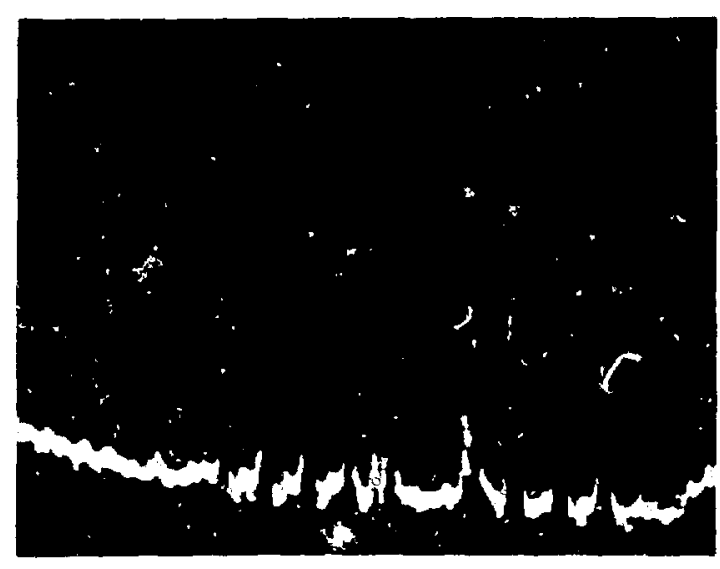

$40 \mathrm{~mA}$

1.75 AMPS

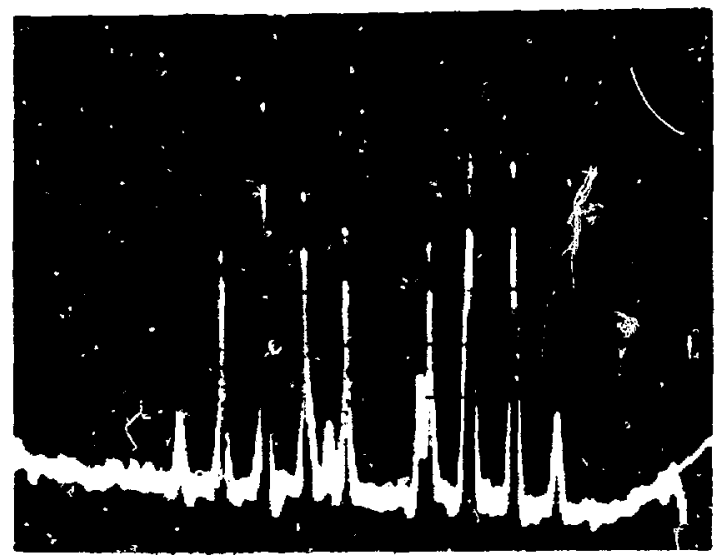

$40 \mathrm{~mA}$
2.7 AMPS

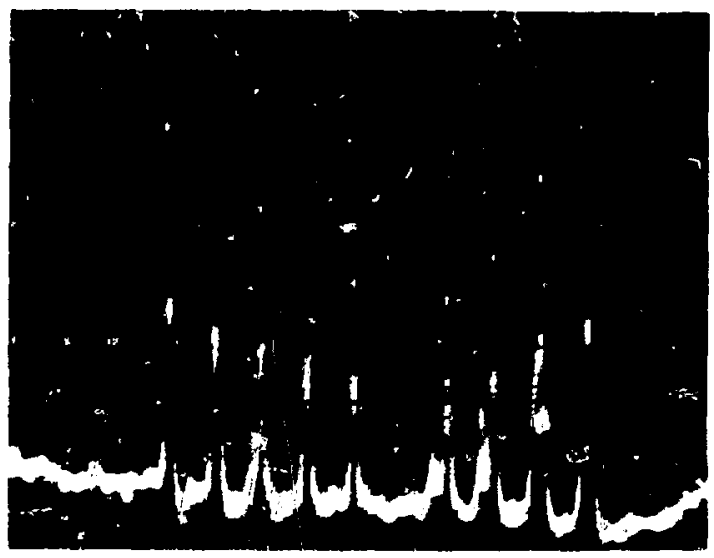

$44 \mathrm{~mA}$

1.75 AMPS

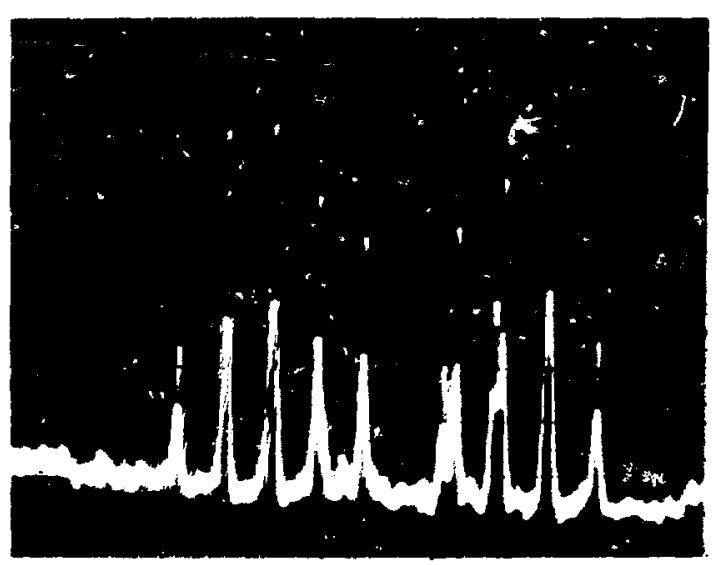

$44 \mathrm{~mA}$

2.6 AMPS

Fig. 26. Vidicon scans.. 
photographs was retained hy calibrating the response of the film. TRI-X Pan of ASA 320 has the minimum film speed for convenient exposures, and its use with $\mathrm{D}-76$ and normal development of 9 min at $68^{\circ} \mathrm{F}$ gives an extended response curve. Figure 27 shows this characteristic curve. The film exposure was made through a calibrated step wedge. A 478 hlue filter was inserted in a tungsten light source as a first approximation to the bluish appearance of the fluorescence from the quartz plate. Aside from reciprocity failure or differences hetween the fluorescence and tungsten light, the characteristic curve shows how to convert densities obtained hy a microdelsitometer into relative light intensities over the surface of the pepner por. The wedges were exposed continuously for $60 \mathrm{sec}$ : whereas tile heam exposures resulted from pulsed light of $10 n \mu \mathrm{sec}$ hursts at a rate of $15 / \mathrm{sec}$ for $60 \mathrm{sec}$.

A typical set of microdensitometer traces is shown in Fig. 28. These traces were taken of picture No. 7A through the centermost horizontal row. $7 \mathrm{~A}$ was obtained with a column current of $44 \mathrm{~mA}$ and an arc magnet current of $1.75 \mathrm{~A}$. Six scans were made tirough this horizontal row. The vertical spacing of these scans is shown in Table $V$. The fourth scan passed roughly through the spot center. The third trace passed along an illuminated grid line which shows up as a large background in comparison with the hackground in the other traces of the set. The largest peak is from the 0.0n5-in.

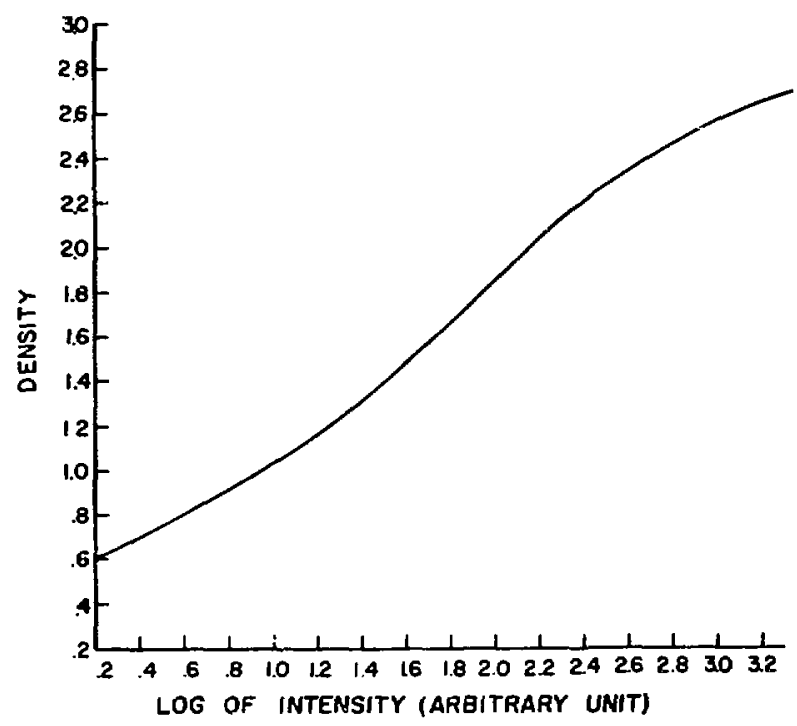

Fig. 27. Micro densitometer normalization curve.

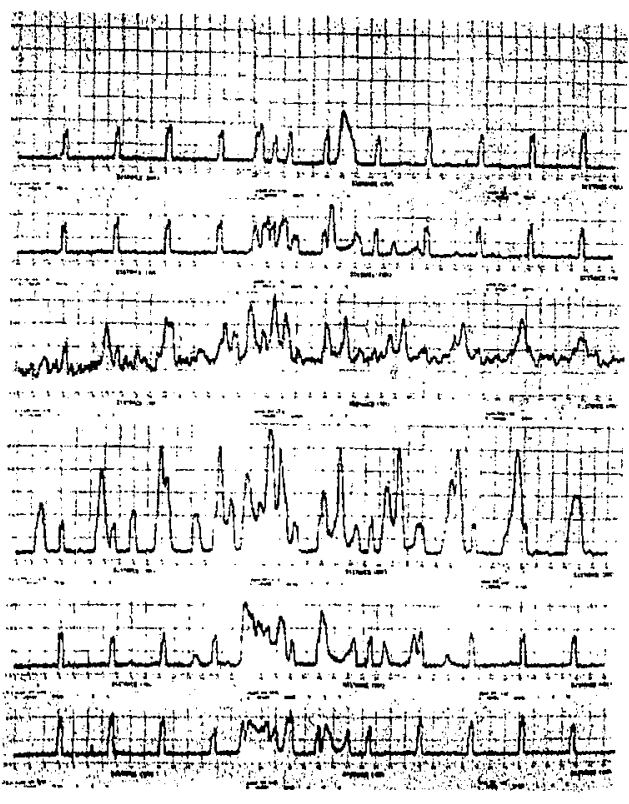

Fig. 28, Photo densitometer scans.

diam locator hole, which lies $0.02 n$ in. to the left of the center of the array. The column axis is 0.051 in. to the right of the indicated center hole, i.e., ahout half way between the center hole and the next hole to the right.

The grid lines show up as the very regular set of peaks especially noticeable in the top and bottom traces of the set. The array of pepper-pot spots representing heam core can he identified in the fourth trace by the seven central peaks, which are very uniform in height. The peak from the locator hole is roughly $20 \%$ higher, and the grid line peaks are ahout 60\% lower.

For the intensity analysis, maximum photographic densities for individual dots were obtained by a horizontal and vertical search over each dot.

TABLF. $V$

Vertical Spacing of Microdensitometer Traces

$\begin{array}{ll}1 & 2.975 \mathrm{~mm} \\ 2 & 2.475 \mathrm{~mm} \\ 3 & 1.894 \mathrm{~mm} \\ 4 & 1.700 \mathrm{~mm} \\ 5 & 1.200 \mathrm{~mm} \\ 6 & 0.700 \mathrm{~mm}\end{array}$


The area on the transparency for which an average density reading is obtained is $0.1 \mathrm{~mm}$ by $0.015 \mathrm{~mm}$. A typical dot diameter, full width at half height on the density curve, is $0.5 \mathrm{~mm}$. Thus, the density is averaged for a rectangle about $1 / 5$ or less of the dot diameter in one direction and $1 / 30$ of the dot diameter in the other.

Averages of the densities were then calculated for each of eleven circular increments centered on the column axis. The average film densities as a function of radius are plotted for four pepper-pot pictures in Fig. 29. A scale for corresponding light intensities taken from Fig. 27 is shown on the right-hand side.

The vidicon data (Fig. 26) and the microdensitometer data (Fig. 29) show qualitative agreement with respect to the effect of extracted ion current and arc magnet current. However, the two measurements are in marked disagreement regarding the actual intensity distributions. The rms radii from the vidicon data are roughly a factor of two greater than those obtained from the microdensitometer. Further, the microdensitometer data indicates a hollow beam, while the other does not. We are as yet unable to resolve these differences.

$A$ bean intensity analysis is hampered by several factors. Only 6 pictures were taken before the pepper-pot holes in the central region were closed by heating, making intensity recovery impossible. Second, only one exposure of $60 \mathrm{sec}$ was made for each parametric setting; this long expo-

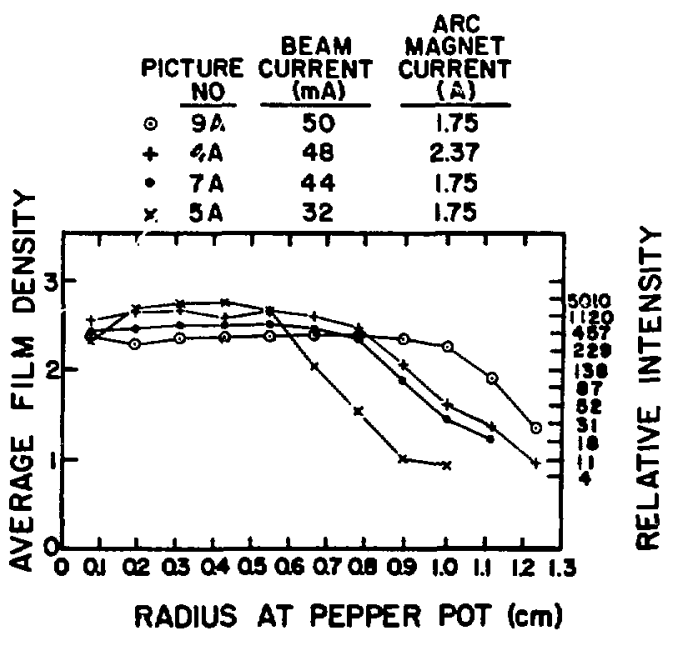

Fig. 29. Film density versus beam radius. sure was required to sufficiently expose the faint beam spots at the periphery of the pepper pot. The central region spot densities then were in excess r. 2.6 where the film begins to saturate. The use of the calibration curve shown in Fig. 27 becomes much less accurate at the high end. Future experiments will require a range of exposures for each parametric setting.

Another factor in the conversion of spot density to light intensity that introduces error is the reciprocity failure of the film. Ten second exposures through the calibrated wedge were made and developed concurrently with each batch of film prccessing. In the actual data films, the 60-sec time rather than the $100-\mu s e c$ pulse time probably dominates the reciprocity failure of the film. Therefore, the 60-sec calibration curve (Fig. 27) is used rather than the 10 -sec curves. The 10-sec curves serve as a measure of development reproducibility. The "GAMMA" or slope of the straight line portion for each of the 14 wedges developed did not vary by more than $10 \%$ from the average. However, a $10 \%$ error in the slope of Fig. 27 could introduce as much as a factor of two in the ratio of light intensity at the center of the beam to the intensity at the edge of the beam. As no wedge curve is available for the first 6 pictures in the experiment (the holes closed after the very first series) the above $100 \%$ uncertainty is believed to be the primary error in the conversion to light intensity. It will be possible in future experiments to generace the calibration curve with the beam itself wher: the first $60 \mu \mathrm{sec}$ of time varying beam phase space can te chopped away.

The conversion of heam intensity to light intensity on quartz must be known for all of the experiments in this paper. The Appendix indicates a maximum instantaneous temperature rise of only $10^{\circ} \mathrm{C}$ for the heam spot images on the quartz plate. This rise is well below the region where the quartz is known to give nonlinear and inverted response. Above a given temperature the light outpit falls with additional heating until thermal glowing brings the light up again. We will assume for the present that heam intensity and fluorescent light output are proportional for the perper-pot data. The microdensitoneter values were average densities over a $10-\mu$ spot at the peak density of each dot. Figure 28 
indicates that the density profile of a single spot on the film does not change significantly with the total beam current through the hole. That is, the profile scales with overall beam current, and the peak density is a good represeritation of the beam current through the pepper-pot hole. These questions can be answered with the same beam calibration experiment described previously.

In conclusion, intensity data are presented in this paper with a factor of two uncertainty in relative intensity of the center areas of the beam to the tail areas. The data can be further refined when a suitable on-line calibration experiment is performed. No errors have been assigned to the vidicon data. There exists the previously noted large systematic difference between the two intensity profile determinations. This difference represents our error in these mosasurements; work will continue towards resolution of this problem.

\section{ANALYSIS OF PEPPER-POT DATA}

To explore systematically the beam phase space at the exit of the column, a set of 104 pepper-pot photographs was taken over a wide range of operating conditions. A list of these photographs giving beam parameters and pertinent comments is presented in Table VI. The A and B series served as preliminary studies to the maid parametric series, which is numbered 1-88. This latter series included as

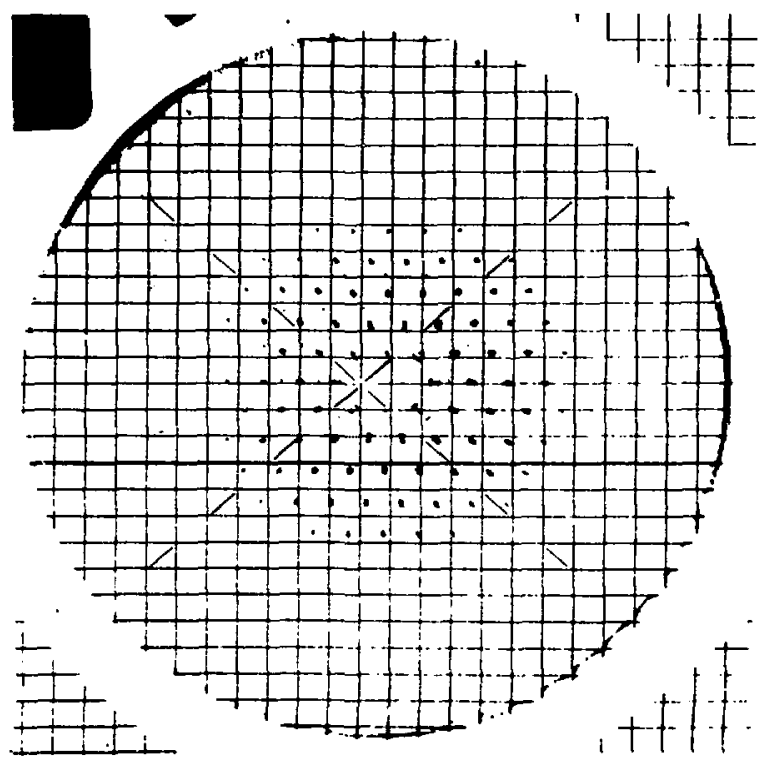

Fig. 30. Pepper-pot picutre No. 26. parametric variables the extracted ion current, arc magnet :urrent, extractor voltage, electron trap voltage, chamber pressure, and pulse width.

Shown in Fig. 30 is pepper-pot picture No. 26, which, according to Table VI, most nearly approximates the injector operating condition. By the time the main parametric series was started, the center-most hole and the locator hole had melted completely shut. The six adjacent holes had partially closed. This effect is evident in Fig. 3n. It is also possible to distinguish between the regular array of spots representing the main body of the beam and the circularly shaped halo images adjacent to them. At the outer edge of the main body, the halo merges with it to create a tear drop shaped pattern.

The photographs were analyzed with the digitizing equipment from the Sherwood Project. Individual points were delineated by cross hairs, and $x$ and $y$ values recorded on punched cards. A computer program $^{5}$ was used to interpolate the data and correct for nonlinearity in background grid resulting from photographic or projection distortions. For these calculations, only the core of the beam was digitized. Because of the large size and symmetrical shape of the data points, a determination of the exact center of each dot involved considerable subjective judgment. The positions of dots near the center of the pictures were probably more accurately determined than those near the outer edges, since the former were fairly circular and halos were discretely separated from the ceritral spots. Toward the edges, the data points assumed a teardrop shape, and errors in defining centers undoubtedly increased. The extreme outer data points were usually so small in size that errors in position were again reduced. All pictures taken with low values of ex. tracted ion current were difficult to read because of the large halos, faintness of data points, and irregular shapes of points.

Following the digitizing and interpolation process, the data were phase space analyzed by computer. This approach was used to allow reduction of all the data points on a given record, thus providing a measure of the accuracy of the onalysis. The code first calculated the center of the bean from symmetry. The data points were then arranged by column and row to match their physical location ss show in Fig. 3n. Position and divergence of each column and 


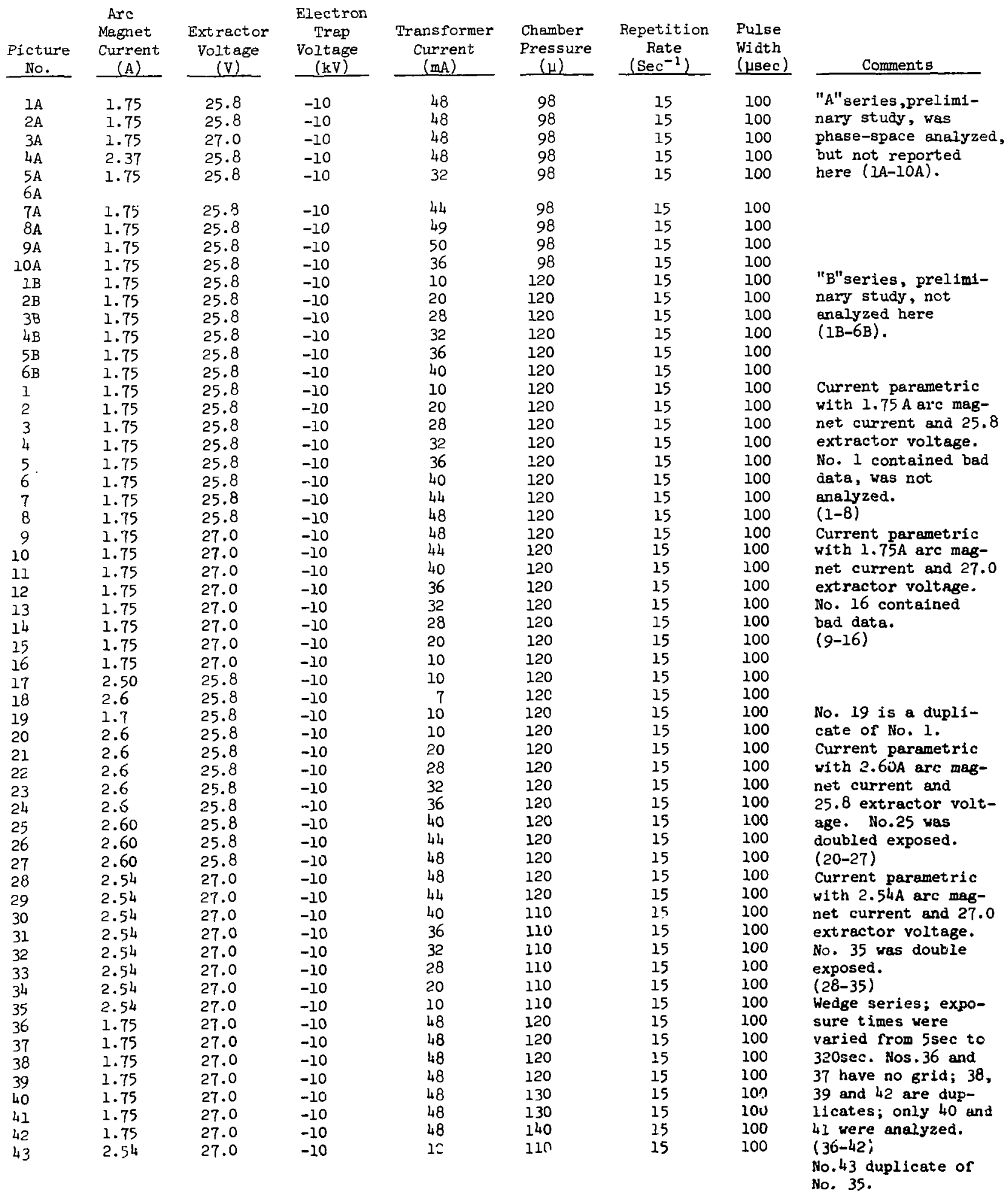


TABLE VI

(Cont inued)

\begin{tabular}{|c|c|c|c|c|c|c|c|c|}
\hline $\begin{array}{c}\text { Picture } \\
\text { No. } \\
\end{array}$ & $\begin{array}{c}\text { Arc } \\
\text { Magret } \\
\text { Current } \\
\text { (A) } \\
\end{array}$ & $\begin{array}{c}\text { Extractor } \\
\text { Voltage } \\
(\mathrm{V}) \\
\end{array}$ & $\begin{array}{l}\text { Electron } \\
\text { Trap } \\
\text { Voltage } \\
\text { (kV) } \\
\end{array}$ & $\begin{array}{c}\text { Transformer } \\
\text { Current } \\
\text { (mA) } \\
\end{array}$ & $\begin{array}{l}\text { Chamber } \\
\text { Pressure } \\
(\mu) \\
\end{array}$ & $\begin{array}{c}\text { Repetition } \\
\text { Rete } \\
\left(\mathrm{Sec}^{-1}\right) \\
\end{array}$ & $\begin{array}{l}\text { Pulso } \\
\text { W1dth } \\
\text { (usec) } \\
\end{array}$ & Comments \\
\hline 44 & 1.75 & 25.8 & -10 & 10 & 110 & 120 & 10 & Short pulse width \\
\hline 45 & 1.75 & 25.8 & -10 & 20 & 110 & 120 & 10 & serles. gepetition \\
\hline 46 & 1.75 & 25.8 & -10 & 28 & 110 & 120 & 10 & rate was Increased \\
\hline 47 & 1.75 & 25.8 & -10 & 32 & 135 & 120 & 10 & for photographle \\
\hline 48 & 1.75 & 25.8 & -10 & 36 & 135 & 120 & 10 & compensation. Nos. \\
\hline 49 & 1.75 & 25.8 & -10 & 40 & 135 & 120 & 10 & 44 and 53 contained \\
\hline 50 & 1.75 & 25.8 & -10 & 44 & 135 & 120 & 10 & bad data. \\
\hline 51 & 1.75 & 25.8 & -10 & 38 & 135 & 120 & 10 & $(44-61)$ \\
\hline 52 & 1.75 & 25.8 & -10 & 51 & 135 & 120 & 10 & \\
\hline 53 & 1.75 & 25.8 & -10 & 10 & 100 & 120 & 20 & \\
\hline 54 & 1.75 & 25.8 & -10 & 20 & 100 & 120 & 10 & \\
\hline 55 & 1.75 & 25.8 & -10 & 28 & 100 & 120 & 10 & \\
\hline 56 & 1.75 & 25.8 & -10 & 32 & 100 & 120 & 10 & \\
\hline 57 & 1.75 & 25.8 & -10 & 36 & 100 & 120 & 10 & \\
\hline 58 & 1.75 & 25.8 & -10 & 40 & 105 & 120 & 10 & \\
\hline 59 & 1.75 & 25.8 & -10 & 45 & 110 & 120 & 20 & \\
\hline 60 & 1.75 & 25.8 & -10 & 48 & 140 & 120 & 20 & \\
\hline 61 & 1.75 & 25.8 & -10 & 50 & 140 & 120 & 20 & \\
\hline 62 & 1.75 & 25.8 & -10 & 10 & 170 & 15 & 100 & Current parametric \\
\hline 63 & i. 75 & 25.8 & -10 & 20 & 170 & 15 & 100 & with wigher chum- \\
\hline 64 & 1.75 & 25.8 & -10 & 28 & 170 & 15 & 100 & ber pressure. \\
\hline 65 & 1.75 & 25.8 & -10 & 32 & 170 & 15 & 100 & $(62-70)$ \\
\hline 66 & 1.75 & 25.8 & -10 & 36 & 170 & 15 & 100 & \\
\hline$<7$ & 1.75 & 25.8 & -10 & 40 & 170 & 15 & 100 & \\
\hline $6 b$ & 1.75 & 25.8 & -10 & 44 & 170 & 15 & 100 & \\
\hline 69 & 1.75 & 25.8 & -10 & 48 & 170 & 15 & 100 & \\
\hline 70 & 1.75 & 25.8 & -10 & 50.5 & 170 & 15 & 100 & \\
\hline 71 & 1.75 & 25.8 & -5 & 10 & 125 & 15 & 100 & Varlous parametric \\
\hline 72 & 1.75 & 25.8 & -5 & 20 & 125 & 15 & 100 & studies uith the \\
\hline 73 & 2.75 & 25.8 & -5 & 28 & 125 & 15 & 1.00 & electron trup at \\
\hline 74 & 1.75 & 25.8 & -5 & 32 & 125 & 15 & 100 & $-10,-5$, and $0 \mathrm{kV}$. \\
\hline 75 & 1.75 & 25.8 & -5 & 36 & 125 & 15 & 100 & No. 80 was double \\
\hline 76 & 1.75 & 25.8 & -5 & 40 & 125 & 15 & 100 & exposed; 8ly is non- \\
\hline $7_{t}$ & 1.75 & 25.8 & -5 & 44 & 125 & 15 & 100 & existent. \\
\hline 78 & 1.75 & 25.8 & -5 & 4.8 & 130 & 15 & 100 & $(71-88)$ \\
\hline 79 & 2.60 & 25.8 & -5 & 48 & 130 & 15 & 100 & \\
\hline do & 2.60 & 25.8 & -5 & 44 & 130 & 15 & 100 & \\
\hline 81 & $2.6 s$ & 25.8 & -10 & 44 & 130 & 15 & 100 & \\
\hline 82 & 2.60 & 25.8 & -5 & 30 & 130 & 15 & 100 & \\
\hline $\begin{array}{l}83 \\
84\end{array}$ & 1.75 & 25.8 & -10 & $1: 4$ & 130 & 15 & 100 & \\
\hline 85 & 1.75 & 27.0 & 0 & 32 & 65 & 15 & 100 & \\
\hline 86 & 1.75 & 27.0 & 0 & 40 & 65 & 15 & 100 & \\
\hline 87 & 1.75 & 27.0 & 0 & 48 & 80 & & & \\
\hline 88 & 1.75 & 27.0 & -10 & 140 & 80 & 15 & 100 & \\
\hline
\end{tabular}


row were then calculated differentially and plotted on film by an $H$ or $V$ (horizontal or vertical). The radius and radiol divergence of the individual dato points were next computed by taking the square root of the sum of the squares of the $x-x^{\prime}$ and $y-y^{\prime}$ data. These were plotted in the first quedrant with osterisks.

Figure 31 shows on example of the resulting phase space plots. The photograph analyzed is again picture No. 26, representing the standard operating condition. The scale is $\pm 20 \mathrm{mrad}$ and $\pm 1.5 \mathrm{~cm}$. As shown by the closeness of the lines arked hori zontal and vertical, the beam phase space appears symmetric with respect to axial rotation. The narrow spread in the asterisk proup lllustrates the adequacy of the calculation and provides ansure of total exror. Bean divergence was estinsted from symetry of the group extrapolated to the position of maximum extent. Visual inspectiol of Fig. 31 indicates an envelope with maximin size of $1.21 \mathrm{~cm}$ and divergence of 15.1 arad. It is again exphasized that Fig. 31 Rives no information regarding bean intensity. This must he obtained from plots such as figs. 27 or 29.

The series of pictures 1-as was analyzed in sialiar fashion. Figure 32 is a plot of divergence and size of the main body for the heans studied in this series. Data points are laheled by picture number.

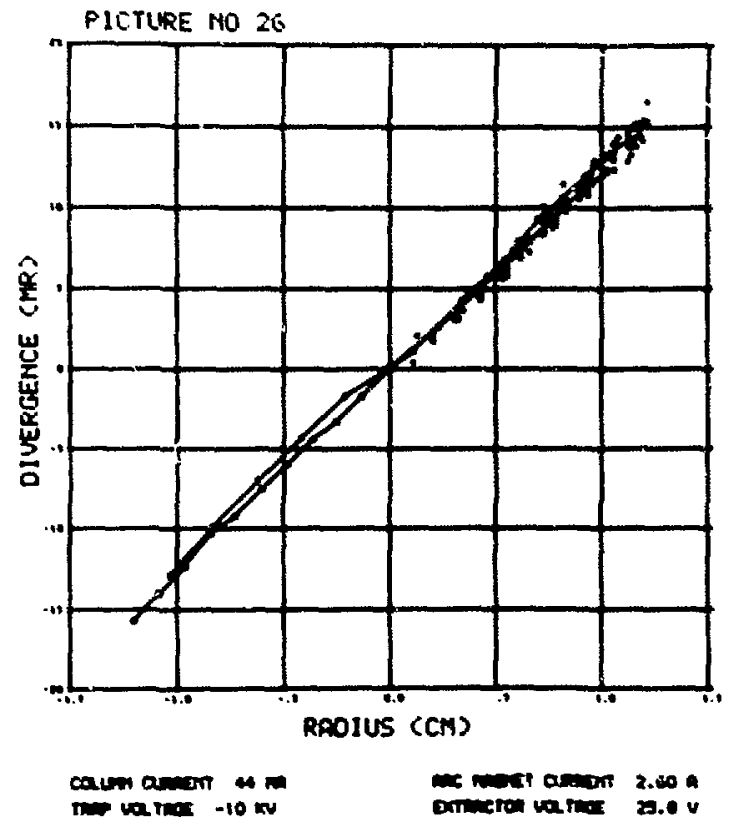

Fig. 31. Phase space analysis of picture No. 26.
Figure 32 serves to dliustrate the only strong correlation noted in this study: increasing column current produces a larger beam envelope and greater divergence. In Fig. 32 the extracted current ranges from 7 al at the lower left-hand corner to 51 at at the upper right. With few exceptions, data points for currents above 40 w lie in tightly clustered group between 15 and 17 mrad, roughly. These date points represent wide range in the other operating parameters. Thus, it appears that the beom phase space is in some sense saturating ot the upper current levels. The intensity measurements discussed in the previous section indicate that it may be possible to effect changes in the intensity profiles of the beam. However, Fig. 32 shows thet the phase space envelope is hasically unaffected by changes in operating parametars other then extracted current.

Some of the results of the principle paranetric studies ore shown graphically in Firs. 33-37. The sali nubers essocisted with esch dete point represent the extracted ion currenes.

Figure 33 indicates a slight correlotion of phose space with arc magnet current ot the higher extracted ion current end of the curve. Arc agnot current has been found to offeet the phase space orientation sliphtly at EML, and to a grester extent ot FMI and FM3. llowever, it is not known whether these effects ore due to the slight change In the phase space envelope or to the density redistrihution indicwed by the intensity measurements. In any case, slikht improvement is found in running ot the higher are mognet current of $\mathbf{2 . 6}$ A. Figure 34 indicates slight shtft down and to the left for the lower extractor voltoge. The opereting point has been redefined to be $25.8 \mathrm{~V}$. Figure 35 indicates that chamber pressure has almost no effect upon the haam phase space. Figure 36 1llustrates the result of en experiment in which pulse width wss reduced. Repetition rate was correspondingly incressed to produce comparable photoprophic inse. There would seen to be high correlation; however, the direction and augnituda of the shifts are such os to sugkest purely extracted ion current effect. That is, 10 usec encompasses the column current transient period, and thus has on sverage lower curren: than the steady-stace portion of the pulse. 
DIVERGENCE (mRAD)

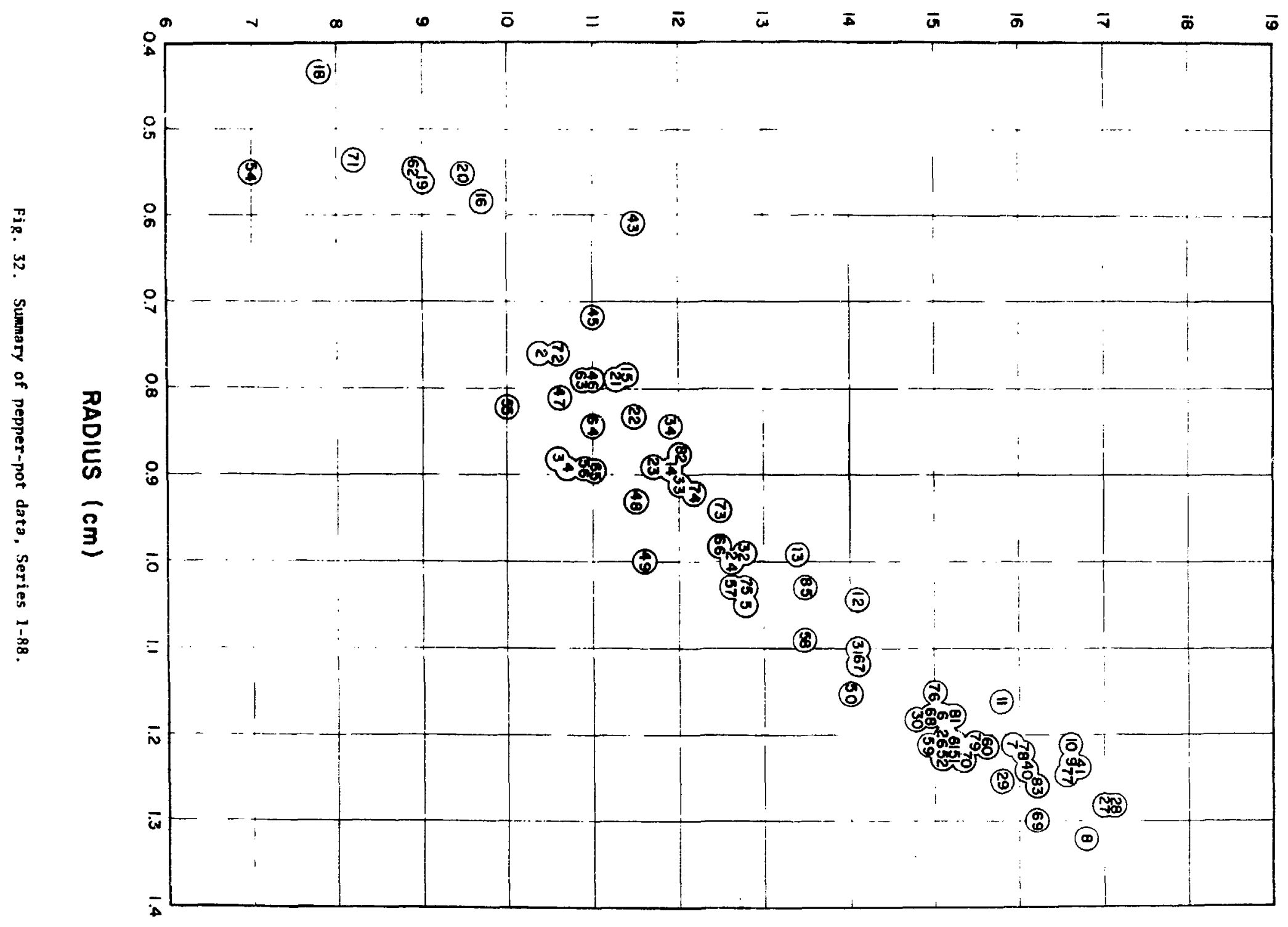



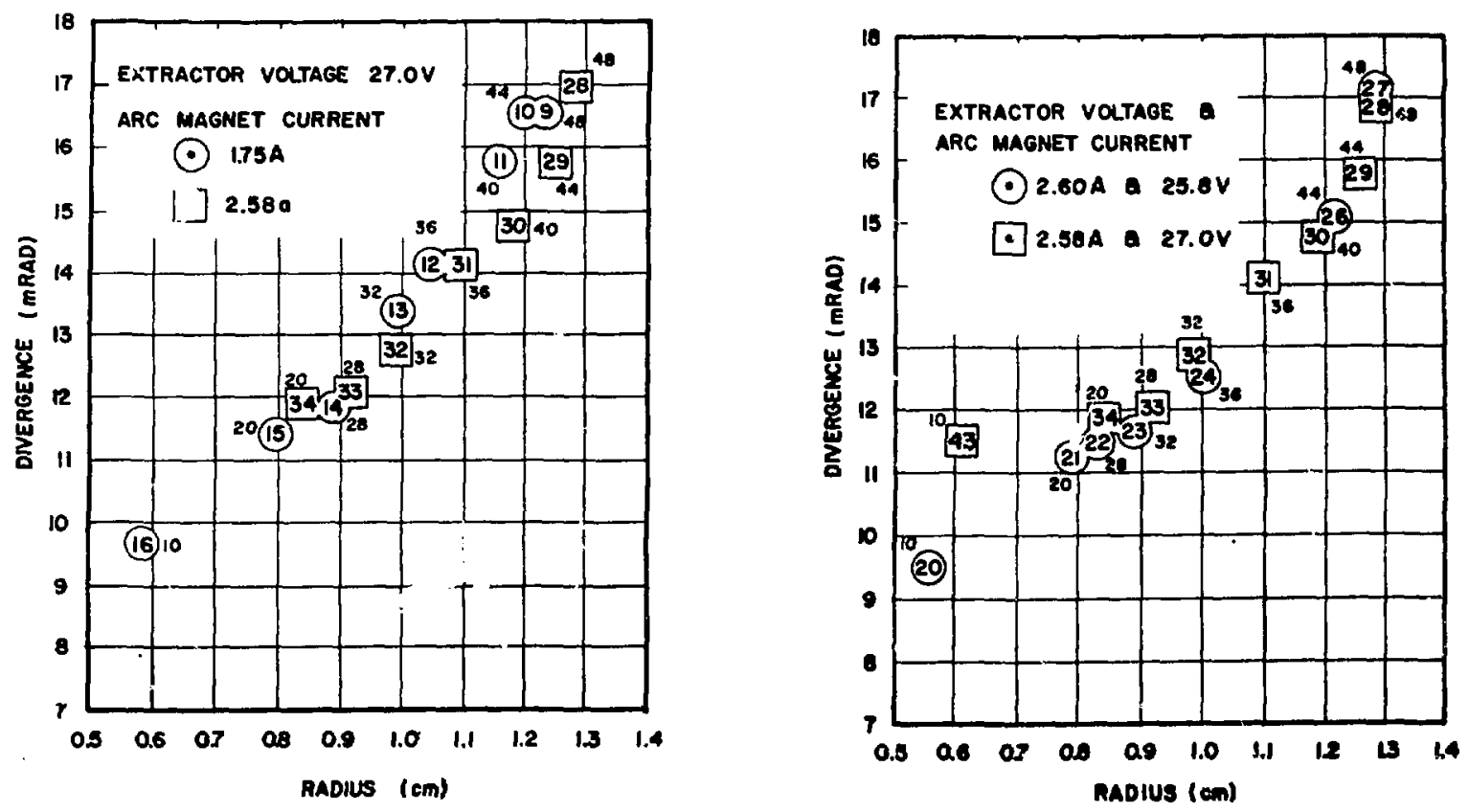

Fig. 33. Beam phase space versus arc magnet current.

Fig. 34. Beam phose space versus extractor voltage.
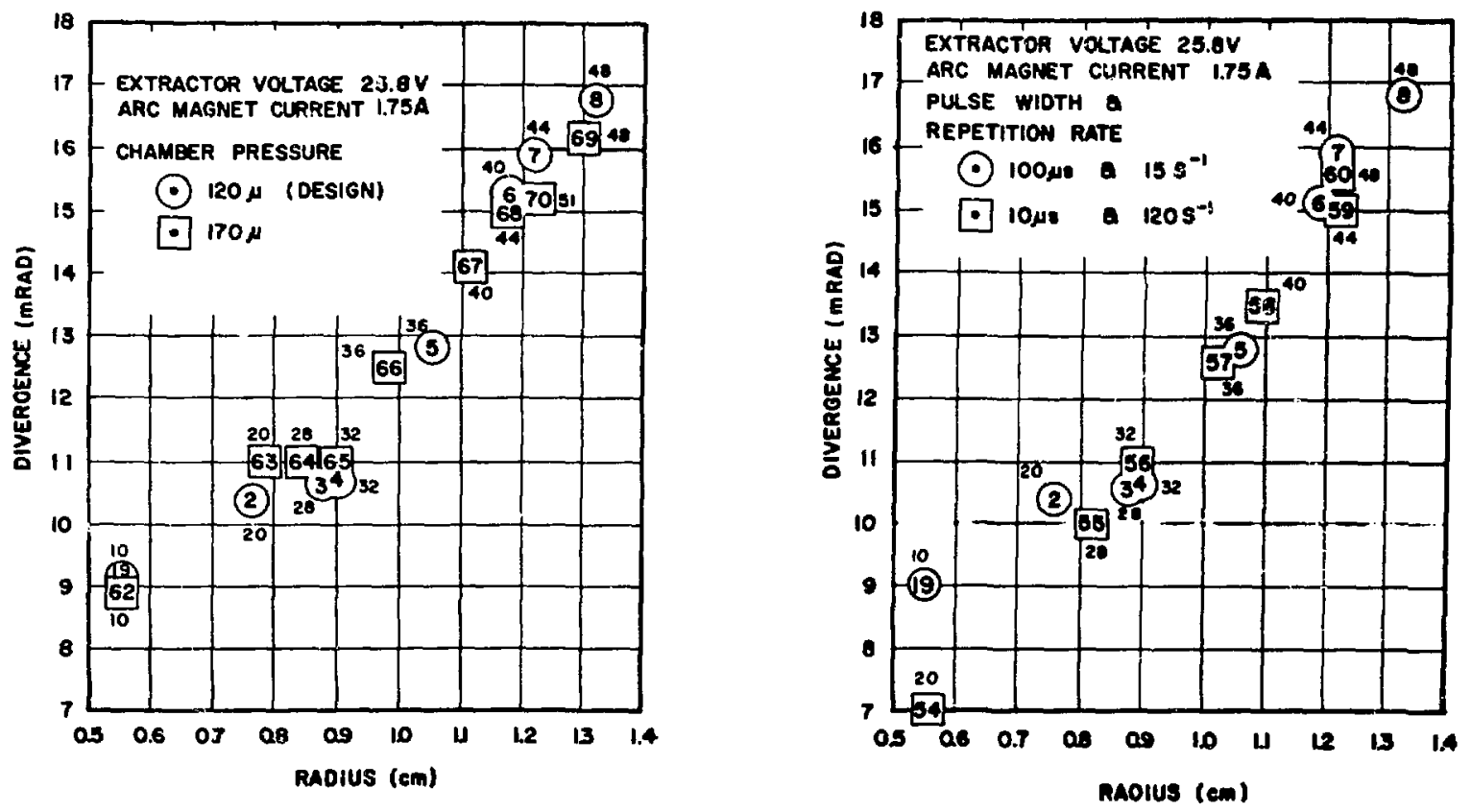

Fig. 35. Beam phase space versus chamber pressure.

Fig. 36. Beam phase space versus pulse width. 
Figure 37 reveals electron trap voltage to have little effect on bean phase space. As previously explained, the pepper-pot plate was biased to $150 \mathrm{~V}$ during these tests. The high electron retention of the plate allowed this experiment to be performed. Trap configuration has previously been noted to produce neasurable phase space rorations at EMl. These would appear not to be due to an effect within the column.

All of the data taken with the pepper pot have been presented as anslyzed, and represent beam properties at a position roughly 5 in. from the exit of the column. We chose to present the data in this way to avoid the possible anbiguity inherent in a transformation. llowever, to allow the possibility of making calculations beginning ot the exit of the coluan, we have trans ormed the data representing the standard operating parameters and various extracted ion currents. These transformed data points are show in Fig. 38. The calculations were done with a radially symuetric Kapchinskyvladinirsky code. Considerotion was taken of the higher charge density of the $\mathrm{II}_{2}^{*}$ species; due to the excellent biasing result, electron neutralizotion effect: were neglected. The colculation over such a short distance should be accurate. Further, - tra.isformation cf a radially symetric hean enve-

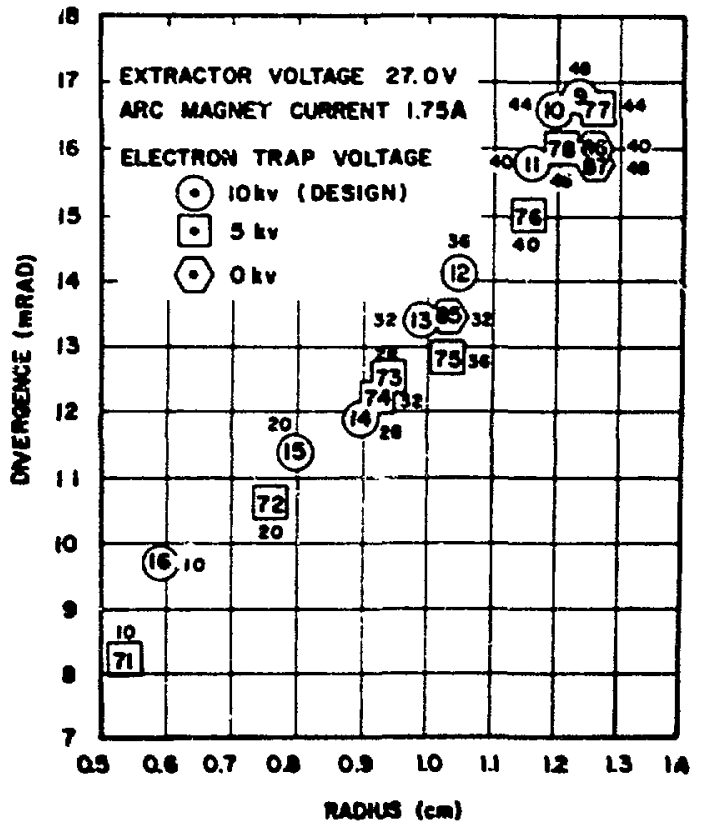

Fig. 37. Beam phase space versus electron trap voltage. lope is not dependent upor, the denstey distribution. The result is that the daca point labeled 26, which represents the standard operating condition, has a size of $\pm 1.03 \mathrm{~cm}$ and a divergence of $\pm 14.6 \mathrm{krad}$ at the center line of the tenth electrods

The tajls have heen defined to have phase spoce distinct from that of the moin body of the heam. To shed more light on this phenomenon; an analysis was done of pictures 21 and 26 for those data points not within the main body phase space. The resules are shown in Figs. 39 and 40 . The phase space region previously designated as main body is shown as the shaded area. The extreaities of this area define the heom envalope. The toils shom represent the outer loct of points in $x-x^{\prime}$ or $y-y^{\prime}$ space and way reflect a radial distribution in phase space. Figure 39 (picture No. 26) represents the design operating condition, while Fir. 40 (picture No. 21) illustrates the result for o lower extracted current of $20 \mathrm{ah}$.

Previous measurements at EMl resulted in ohservations of heam steering, or displacement of the bean off axis, as a function of extracted ion current. In an attempt to find the surce of this phenomenon, a record was kept of the calculated bean centers ohtained from the pepper-pot photographs. These data points were plotted versus

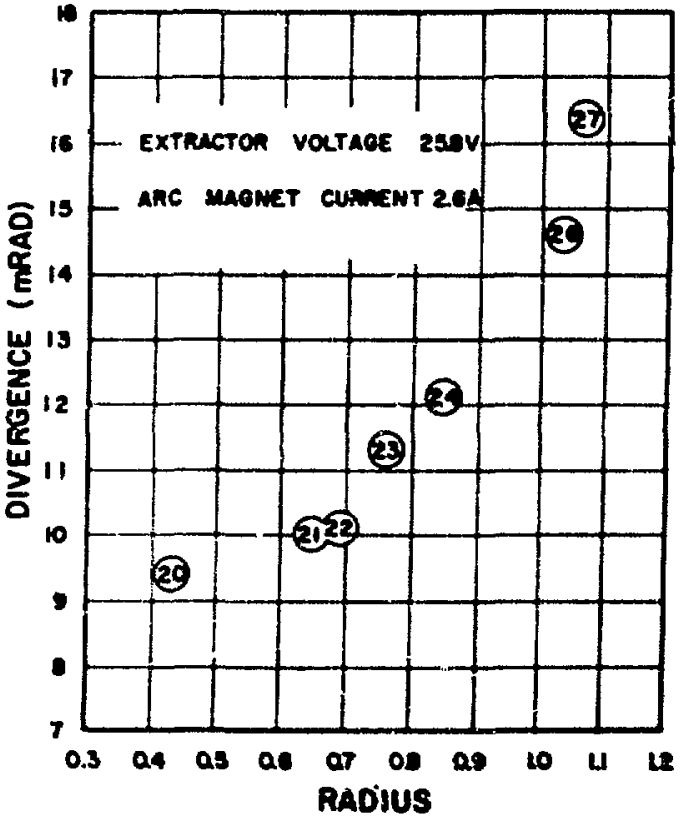

Fig. 38. Standard operatink condition phase space tronsformed to the exti of the colum. 
various operating perameters, including extracted current. The results show that beam position cannot be correlated with any of the operating parameters. Fluctuations appear randon and prohahly reflect the use of a symetry calculation in determining the beam center. In other words, there is no bean steering effect, at least up to this point along the beam line. Further, the center of the beam seems to coincide very closely with the axis of the accelerating column previously determined by $j$ ig eransit measurements.

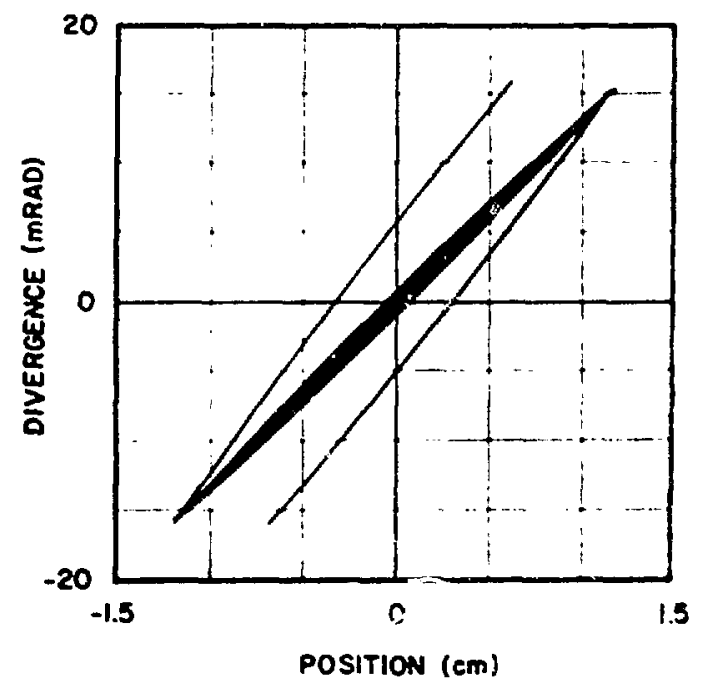

Fig. 39. Transverse phase space for picture No. 26.

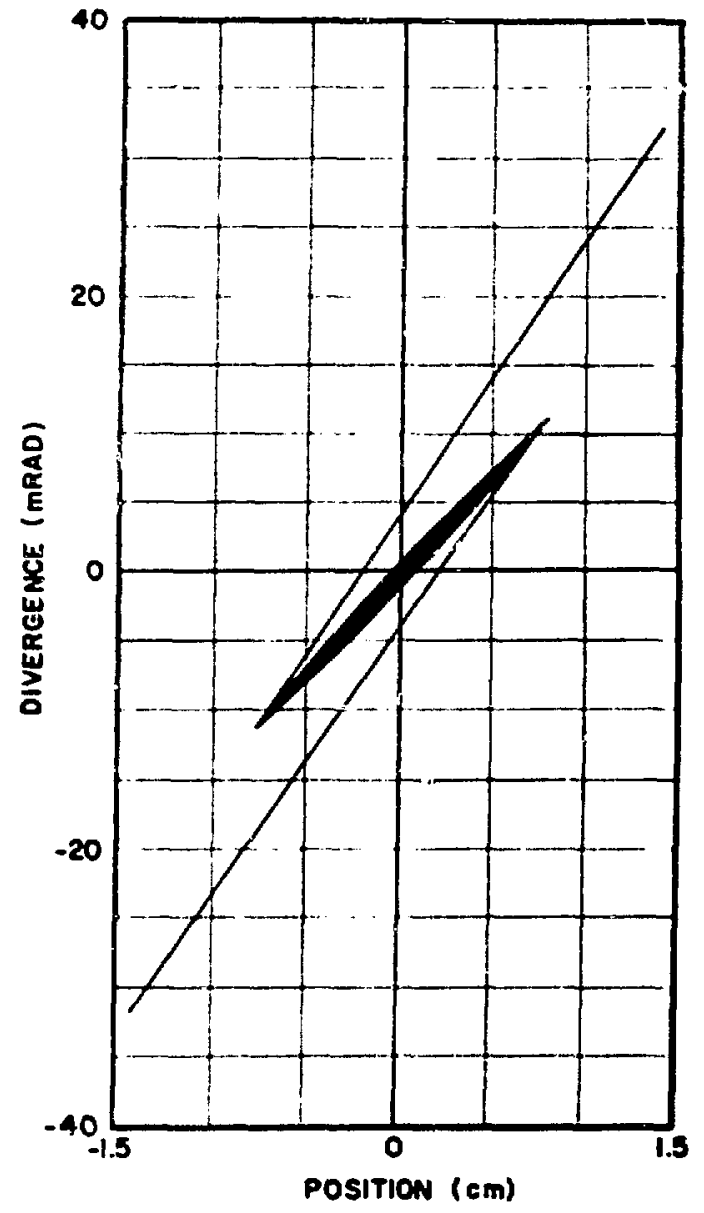

Fig. 40. Transverse prase space for picture No. 21. 


\section{APPENDIX}

\section{QUARTZ Plate TEMPERATURE Calculations}

During the tests conducted with the quartz plate viewing screens, it was observed thar, at high power ievels, the light output from the quartz decreased over a period of several seconds. These chservations were first made visually and lacer confirmed using the vidicor insensity scanner. It was also observed that, as the pulse length was increxsed to 500 usec, the central black reging in the hean progressively increased until finally a bright spot was observed in the center of the beam. Visual observation of the screen confirmed that the quartz was glowing red hot at this point, and subsequent inspection of the screen showed that the quartz had been partiaily eaten away. These observations suggest that there is significant heating of the quartz plate during the bean pulse, and that the apparent hollow structures at low current may he due to decreased fluorescence of the quartz. To investlgate this, calculations have heen made of the temperature rise at the surface of the quartz. No data, except the qualitative ohservation of decreased light output at higher bean power, have heen found to confirm the decrease in fluorescence of the quartz with tempereture.

Estinates of temperature rise in the quartz can be obtained by assuaing the quartz hehaves as a sewi-infinite solid with radiation impingisig on its front surface. Since the range of $750 \mathrm{kV}$ protons is only several microns in quartz, this is a valid assumtion during any one hean pulse. An independent calculation must be done to determine the average tentierature rise of the plate.

Using the results for this model, we have

$\Delta T=\frac{2 F_{0}}{K} \frac{K r}{\pi}$

$\Delta T$ - Temperature rise at the surface of the solid

$F_{0}$ - Themal flux per unit orea per unit time

X - Therwal conductivity

$K=\frac{K}{D C}-$ Thermal diffusivity

t - Time after the heating at rate $F_{0}$ starts.

For quarez, we have

$\mathrm{K}=0.03 \mathrm{cal} / \mathrm{cm}-\mathrm{sec},{ }^{\circ} \mathrm{C}$

$D=2.65 \mathrm{~g} / \mathrm{cm}^{3}$

$c=0.18 \mathrm{cal} / \mathrm{R}-\cdots \mathrm{C}-$.

Thus, $x=0.063 \mathrm{~cm}^{2} / \mathrm{sec}$.

The results of the surface heating for 20 -usec and Inn-usec heam pulses are tabulated in Tab? $A . I$. we note that the naximu excursion during a buam

TABLE A.I

QUARTZ PLATE TEMPERATURE EXCURSION CALCULATIONS

\begin{tabular}{|c|c|c|c|c|c|c|c|}
\hline I & $\begin{array}{l}R \\
\mathrm{CP} \\
\end{array}$ & $\begin{array}{l}\text { Area } \\
\text { cas }\end{array}$ & $\begin{array}{c}\text { Pover } \\
\mathrm{kin} \\
\end{array}$ & $\begin{array}{r}F_{0} \\
\mathrm{~kW} / \mathrm{cm} \\
\end{array}$ & $\begin{array}{c}F_{0} \\
\mathrm{kcal} / \mathrm{co}-\mathrm{sec} \\
\end{array}$ & $\begin{array}{c}\Delta \mathrm{T}(20 \text { usec }) \\
0= \\
\end{array}$ & $\begin{array}{c}\Delta T(100 \text { usec }) \\
{ }^{\circ} \mathrm{C} \\
\end{array}$ \\
\hline 2.0 & 0.25 & 0.26 & 1.5 & 7.65 & 1.83 & 73 & 163 \\
\hline 6.0 & 0.35 & 0.39 & 4.5 & 11.7 & 2.80 & 118 & 264 \\
\hline 10.0 & 0.58 & 1.06 & 7.5 & 7.1 & 1.70 & 72 & 162 \\
\hline 20.0 & 0.92 & 2.68 & 15.0 & 5.6 & 1.34 & 57 & 227 \\
\hline 30.0 & 1.34 & 5.65 & 22.5 & 4.0 & 0.96 & 41 & 31 \\
\hline 40.0 & 2.63 & 8. 35 & 30.0 & 3.6 & 0.86 & 3́́ & 81 \\
\hline 44.0 & 1.69 & 3.98 & 33.0 & 3.7 & 0.88 & 37 & 83 \\
\hline 46.0 & 1.77 & 3.83 & 36.5 & 3.5 & 0.84 & 36 & 80 \\
\hline
\end{tabular}


pulse occurs at curtents newr 6 al because the specific thermal flux becomes large as the main central spot size of the bean decreases.

In order to estinate the werage temperature rise, boundary conditions are ixposed by assuming the perimeter plate to be aintained at a constant temperature $T_{0}$. The plate thickness is sufficiently snall compared to the diameter so that the heat flow can be considlered radial. The entire cent. al region of thic quart: out to beat radius $r_{0}$ is saken to be unifor temperature $T_{a}$. For the experiments carried out in these tests, alse repetition sate of 15 pps was used; thus th: duty factor for the 20 - $\mu$ sec case is $0.3 \times 10^{-3}$ ar. 1 for the 100 -usec case is $1.5 \times 10^{-3}$. The average power input $H$ to the quartz plate is then simply the product of the instantaneous beda power times the appropriate duty factor. We then equate the average power input to the radial hent. flow in the unheated region. The result is

$$
\begin{aligned}
& -K A \frac{d T}{d r}=11 \quad \begin{array}{l}
11=(\text { Power) } \times \text { (Duty Factor) } \\
R_{0}=4.45 \mathrm{~cm}
\end{array} \\
& T=0.635 \mathrm{~cm} \\
& -d T=\frac{\ddot{d}}{k A} d x \\
& -\int_{i}^{T_{0}} d T=\int_{r}^{R_{0}} \frac{\| l}{2 \pi K T} \frac{d r}{r}=\frac{n}{2 \pi K T} \ln \left(\frac{R_{0}}{r}\right) \\
& \left(T-T_{0}\right)=\frac{H}{2 K T} \ln \left(\frac{R_{0}}{T}\right) \text {. }
\end{aligned}
$$

Thus, the peak tempersiture at the surface of the quartz plate is given approxinotely by the sim of the two calculations. Results are tabulated in

\begin{tabular}{|c|c|c|c|c|c|c|c|}
\hline I & 8 & $\ln \left(R_{0} / R\right)$ & Power & н(20нsec) & $\mathrm{T}_{\mathrm{avg}}(20 \mu \mathrm{sec})$ & H(100usec) & $T_{\text {avg }}(100$ sec $)$ \\
\hline $\mathbf{m A}$ & $\mathrm{cm}$ & & scel/sec & $\mathrm{cal} / \mathrm{sec}$ & ${ }^{\circ} \mathrm{C}$ & $\mathrm{cal} / \mathrm{sec}$ & ${ }^{\circ} \mathrm{C}$ \\
\hline 2.0 & 0.25 & 2.88 & 0.36 & 0.11 & $1.6: 3$ & 0.55 & 8.5 \\
\hline 6.0 & 0.35 & 2.54 & 1.08 & 0.32 & 4.31 & 1.60 & 21.5 \\
\hline 10.0 & 0.58 & 2.04 & 1.79 & 0.54 & 9.2 & 2.58 & 44.0 \\
\hline 20.0 & 0.92 & 1.57 & 3.58 & 1.07 & 14.0 & 5.37 & 70.5 \\
\hline 30.0 & 1.34 & 1.20 & 5.36 & 1.60 & 16.0 & B.05 & 80.5 \\
\hline 40.0 & 1.63 & 1.0 & 1.18 & 2.15 & 17.9 & 10.8 & 90.1 \\
\hline 44.0 & 1.69 & 0.96 & 7.90 & 2.37 & 19.0 & 11.8 & 94.5 \\
\hline 46.0 & 1.77 & 0.92 & 8.27 & 2.48 & 18.3 & 12.4 & 91.5 \\
\hline
\end{tabular}
Table A.II. At equilibriu, the thermal profile of the front surface of the quartz is shown in Fig. A.1.

TABLE A.II

AVERAGE TEMPERATURE RISE IN QUARTZ PLATE

The characteristic tine for heat transfer to occur in the quartz plate can be estimazed by calculoting the time required for the back surface of the plate to rise to $1 / 2$ its average steady state temperature. Using the results of the theory ${ }^{7}$ for a seai-infinite solid, one obtains

$$
\begin{aligned}
& \frac{x}{2 \cdot \sqrt{k t}}=0.477 \quad x=0.635 \mathrm{~cm} \\
& \tau_{s_{2}}=\frac{x^{2}}{4 K(0.477)^{2}} \\
& \tau_{l_{2}}=7.0 \text { sec for this quartz plate. }
\end{aligned}
$$




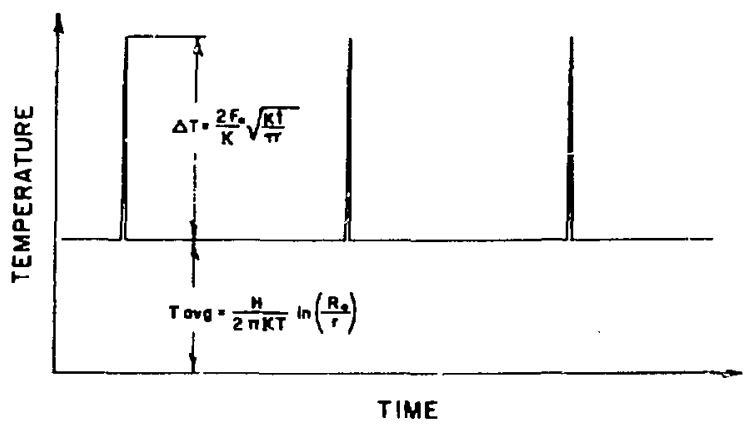

Fig. A.1. Temperature of the front surface of the quartz plate.

This is in qualitative agreement :-ith experiment in that there was a decreased light output over several seconds when the pulse length was increased.

Results of these calculations are shown in

Table A.III. Maximum temperature at the front surface is relatively independent of the beam current, but the maximum excursion is much higher for the low current beams. At the higher currents, the entire

TABLE A.III

SURFACE T'MPERATURE RISE IN THE QUARTZ PLATE

20usec Pulses

1004sec Pulses

\begin{tabular}{|c|c|c|c|c|c|c|}
\hline 1 & $\mathrm{~T}_{\text {avg }}$ & $\Delta T$ & $T_{\max }$ & $T_{\text {avg }}$ & $\Delta T$ & $T_{\max }$ \\
\hline$m i$ & ${ }^{\circ} \mathrm{C}$ & ${ }^{\circ} \mathrm{C}$ & ${ }^{\circ} \mathrm{C}$ & ${ }^{\circ} \mathrm{C}$ & ${ }^{\circ} \mathrm{C}$ & ${ }^{\circ} \mathrm{C}$ \\
\hline$\therefore$ & $1 . i$ & 73 & 74.7 & 9 & $i 63$ & 172 \\
\hline 6 & 4. & 118 & 122.3 & 22 & 264 & 286 \\
\hline 10 & 9.2 & 71.5 & 80.7 & 44 & 160 & 204 \\
\hline 20 & 14.0 & 56.8 & 70.8 & 71 & 127 & 198 \\
\hline 30 & 10.0 & 40.5 & 56.5 & 81 & 91 & 172 \\
\hline 40 & 17.9 & 36.4 & 54.3 & 90 & 81 & 171 \\
\hline 44 & 19.0 & 37.1 & 56.1 & 95 & 83 & 178 \\
\hline 160 & 18.3 & 35.6 & 53.9 & 92 & 82 & 182 \\
\hline
\end{tabular}

plate becomes hot but there is a much smaller temperature variation during the beam pulse. Since it is believed that, above a certain point, light output decreases with increasing temperature, it would appear that the apparent hollows that occur at low bean currents are due at least in part to the high temperature excursion that occurs during the beam pulse, and that at the higher currents the uniform decreases in light output which is observed over the entire beam spot can be attributed to the avezage temperature rise.

Additional photographs were taken for which only the pulse length was varied. In Figs. A.2 and A.3 we see photr.graphis of beams of 40 - and $42-m$ current. A hot spot is ohserved at low pulse length which becones hollow at higher pulse lengths, presumahly because of the heating of the quartz. In Figs 1.4 and A.S, we see a $6-m h$ and $10-m h$ cross-sections, respectively, together with intensity profiles from the vidicon intensity scanner. The central hollow is also believed to be due to the large temperature excursion of the plate rather than a time dependent hollow in the beam. The ring structure and square apnearance of the central hollow are still not understood.

For the pepper-pot work, the temperature excursions are much smaller. The average heating effect is neglizible. The peak heating is reduced by the divergence of the bean. A typical spot size of $0.010 \mathrm{in}$. results from $\mathbf{0 . 0 0 2 - i n}$. hole, thus giving a reduction in intensity of 25 . Hence $10^{\circ} \mathrm{C}$ maximin temperature rise would be expected.

\section{ACIGNOWLEDGFMFNTS}

The authors wish to thank D, P. Escudero, C. R. Melnteer, M. M. Kelly, T. E. Newlin and J. R. Parker for their assistance in these experiments. 


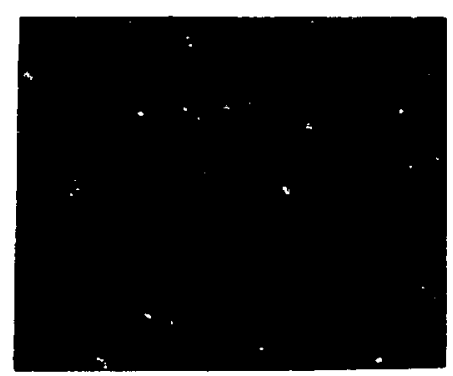

10 usec

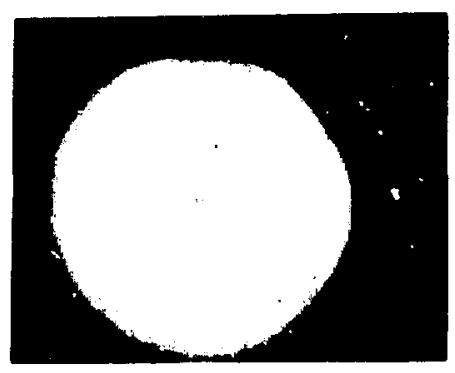

80 use

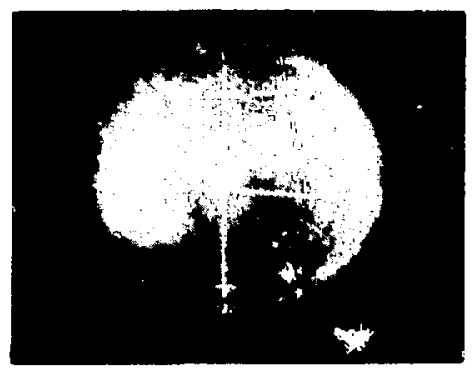

20 ures

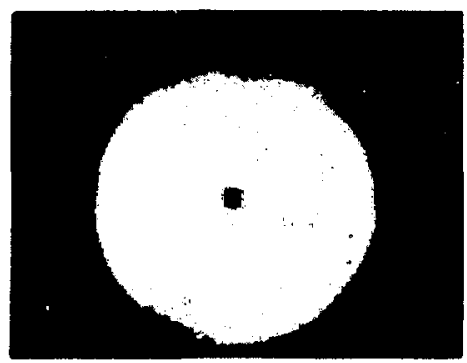

100 uses

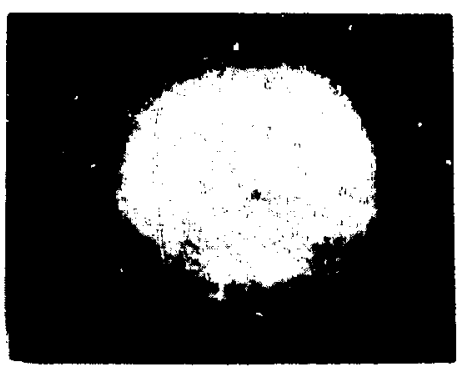

40 unes

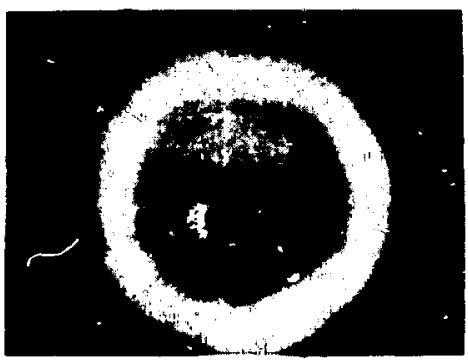

160 unes

Fig. A.2. Bean cross section with arc mugnet current $1.50 \mathrm{~A}$ and hean current $40 \mathrm{~mA}$.

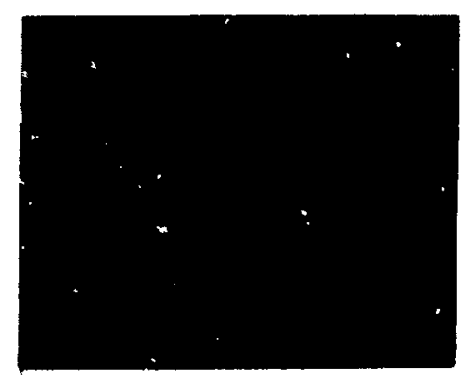

10 ures

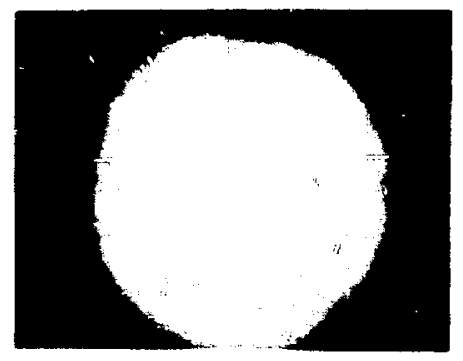

80 urec

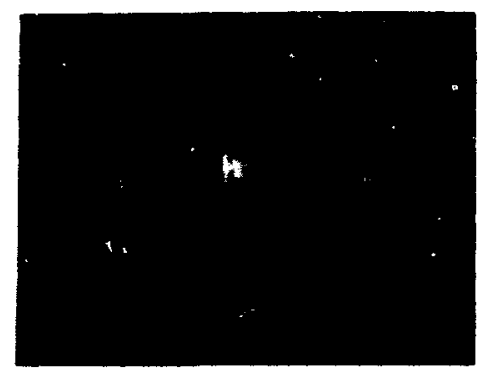

20 4806

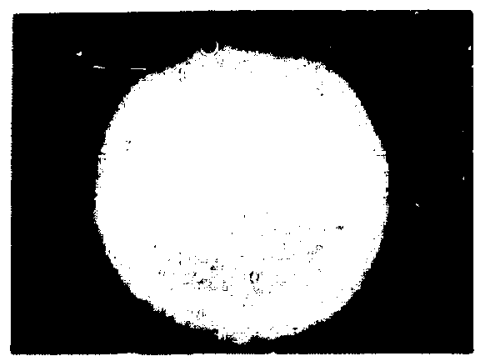

100 use

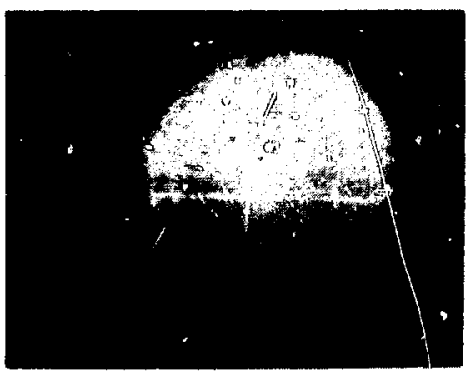

40 usee

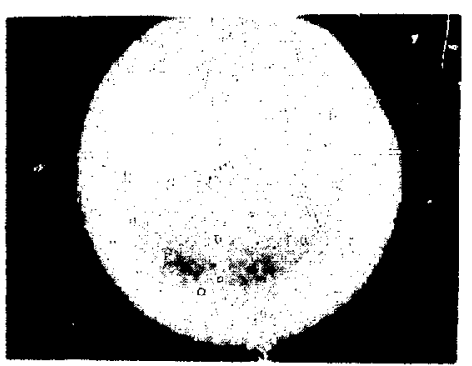

160 usee

Fir. A.3. Bean cross section wh arc mognet current $1.50 \mathrm{~A}$ and bean current $42 \mathrm{ah}$. 

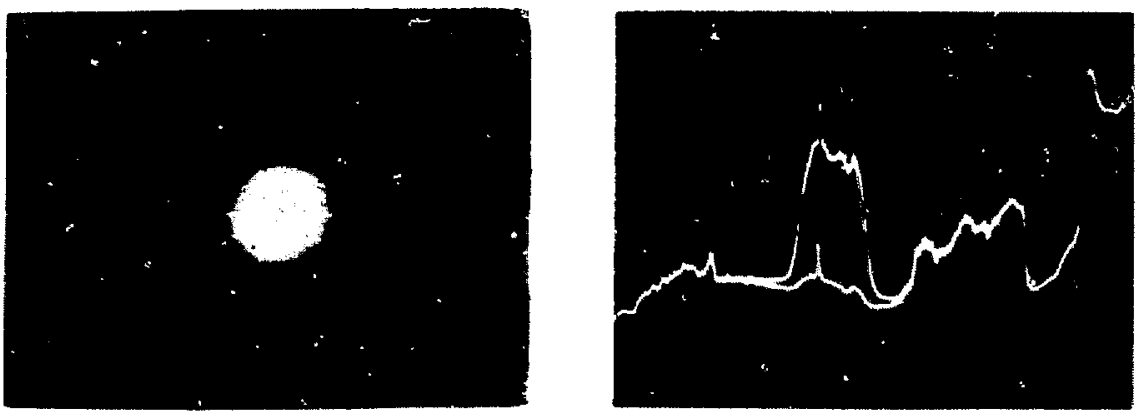

\section{0 usec PULSE LENGTH}
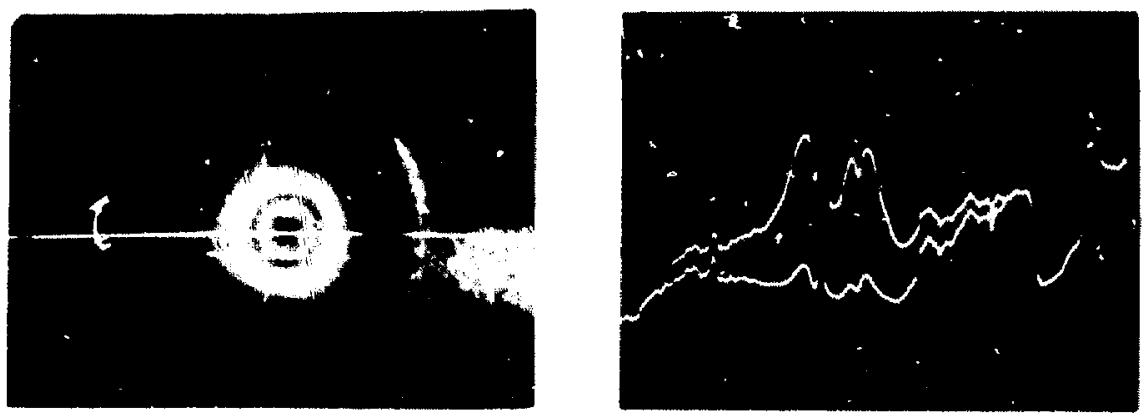

60 usac PULSE LENGTH
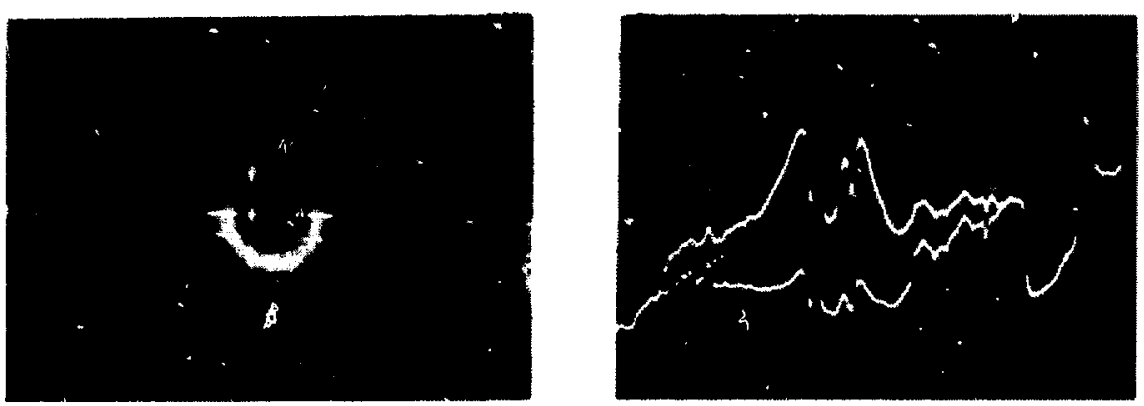

100 HSEC PULSE LENGTH

BEAM CURRENT - 6 MA ARC MAGNET CURRENT -1.5 AMPS

Fig. A.4. Beam cross sections $16 \mathrm{in}$. from exit of accelerating colum. 

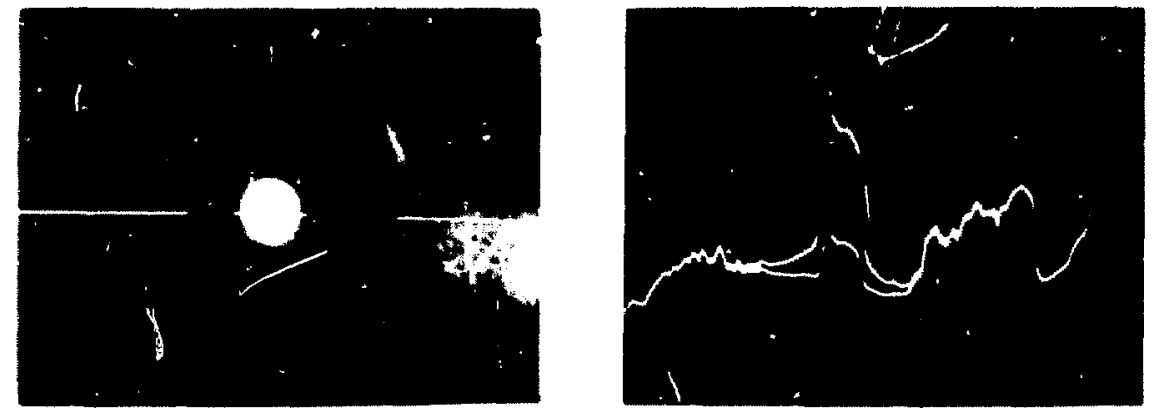

20 usoc PULSE LENGTH
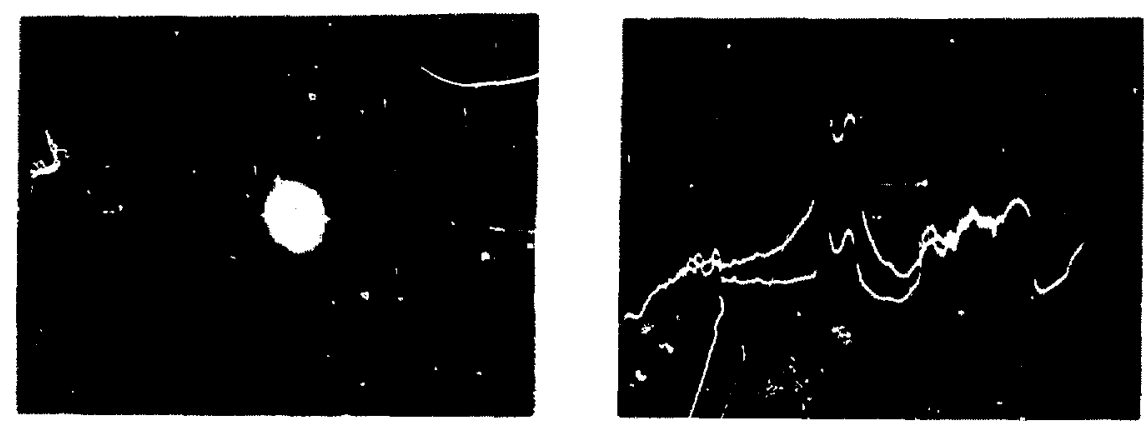

60 Hsec PULSE LENGTH
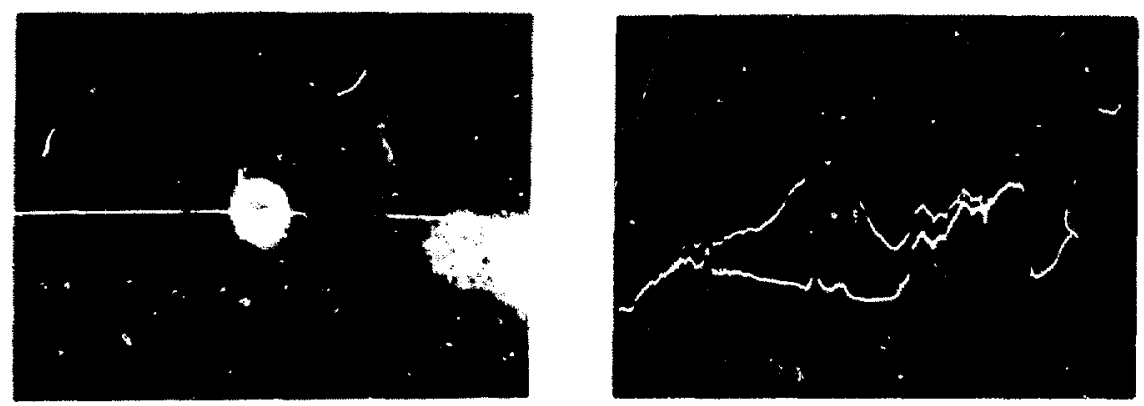

100 USEC PULSE LENGTH

BEAM CURRENT - $10 \mathrm{~mA}$ ARC MAGNET CURRENT- 1.5 AMPS

FtR. A.5. Beam cross sections 16 in. from exit of accelerating column. 


\section{REFERFNCES}

1. B. Goplen and R. R. Stevens, Jr., "Studies on the Bean Dynanics of the High Intensity Proton Bean Tine in the Injector Complex at Lupf." unpublished report.

2. C. Robert Enigh, 'The 'Pierce' Geometry, An Accelerating Colum Design," Proc. 1966 Linear Acceleretor Conf.. Lh-3609, p. 398 (1966).

1. C. R. Emigh, "Mean Transport in : 'Pierce' Accelerating Column," to be published.
4. J. R. Parker, P. W. Allison, D. W. Mueller and R. R. Stenvens, "Besen Profile Monitoring and Anelysis by Television." IEEE Trons. on Nucl. Sci., NS-18, 3, Pp. $935-936$ (1971).

S. R. A. Jameson and R. S. MIIIs, "Two-Dimensional Search und Interpolation on - Distorted Rectengular Grid. Prokran ST(G2D." LA-4891-MS, Los Almos Scientific Lhoratory (1972).

6. Carslaw and Jueger, Conduction of llest in Solids, Oxford University Press, p.75 (1959).

7. Ihid., p. 60 . 